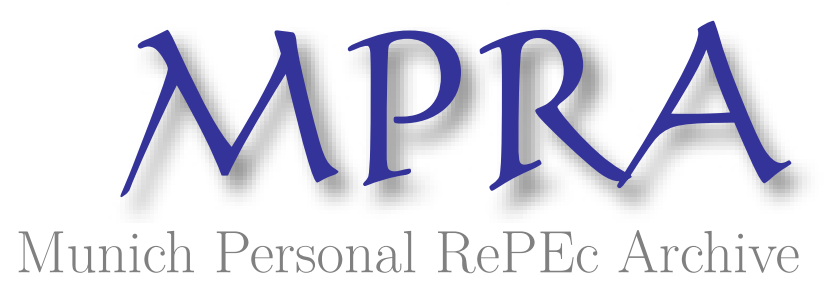

\title{
Threshold cointegration and spatial price transmission when expectations matter
}

Lence, Sergio and Moschini, Giancarlo and Santeramo, Fabio Gaetano

Iowa State University, Iowa State University, University of Foggia

14 July 2017

Online at https://mpra.ub.uni-muenchen.de/80202/

MPRA Paper No. 80202, posted 17 Jul 2017 16:31 UTC 


\title{
Threshold Cointegration and Spatial Price Transmission when Expectations Matter
}

\section{Sergio H. Lence, GianCarlo Moschini and Fabio Gaetano Santeramo*}

\begin{abstract}
We examine the performance of the threshold cointegration approach, specifically BandTVECM, to price transmission analysis in an explicit context where trade decisions are made based on expectation of final prices, because trade takes time. We find that, following a standard inference strategy, a large portion of three-regime cases are not identified as such. Results show that transfer costs are systematically underestimated, particularly in threeregime models. The speed of price transmission is also biased in three-regime models. Furthermore, inferences about occurrence of trade are poor, with estimated models suggesting far lower market integration than is true in the data generating process.
\end{abstract}

Keywords: Band-TVECM, market integration, price transmission, threshold cointegration, transfer costs.

JEL codes: Q11, F17, C32

This version: June 27, 2017

* Lence is Professor and Marlin Cole Chair of International Agricultural Economics, Department of Economics, Iowa State University. Moschini is Professor and Pioneer Chair in Science and Technology Policy, Department of Economics and CARD, Iowa State University. Santeramo is Ricercatore, University of Foggia, Italy. Senior authorship is not assigned. 


\section{Threshold Cointegration and Spatial Price Transmission when Expectations Matter}

\section{Introduction}

Prices reflect competing equilibrating forces at work in a market setting, condense complex and decentralized information, and provide vital signals for the allocation of resources by economic agents. Much can be learned from price data, but, because goods and services are heterogeneous with respect to form, space, and time, price analysis can be challenging. In addition to sophisticated econometric techniques, accurate inference may require a clear understanding of industry, and awareness of relevant policies and institutions. The interaction of such factors in the analyst's model is just as important. Efforts to investigate the scope and applicability of the expanding economist's toolkit are essential, as methods and techniques appropriate in one setting might prove inadequate when seemingly minor conditions or assumptions are changed. In this paper, we revisit a popular approach to the analysis of price transmission, the threshold autoregressive model, and assess its performance in an explicit spatial equilibrium context.

Spatial links between prices have long been of interest in agricultural economics. Earlier work is summarized and discussed in Fackler and Goodwin (2001). A central concept is the so-called Law of One Price (LOP), whereby prices in two markets linked by trade tend to be equalized by arbitrage - apart, of course, for the cost of carrying out such arbitrage, which includes transport and other transaction costs (collectively referred to as "transfer costs" hereafter). Important questions regarding market integration, market efficiency, and the effectiveness of policies can relate to how exactly prices are transmitted between markets. Wright and Williams (1989) and Coleman (2009b) highlight the role of storage activities and inventory management in determining the spatial constellation of prices. Shiue (2002) also studies physical arbitrage, with an emphasis on the connection between trade and intertemporal arbitrage within the framework of spatial price transmission. Coleman (2009a) and Stephens et al. (2011) explore the importance of information on trade capacity constraints and on trade flows in analyses of spatial price transmission. Myers and Jayne (2012) identify the differing impacts on price transmission of private sector trade and government behavior. 
The concept of cointegration has played a central role, at least since Ardeni (1989), in the analysis of price transmission (e.g., García-Germán et al., 2016). In particular, following the seminal papers by Balke and Fomby (1997) and Hansen and Seo (2002), many LOP econometric studies have adopted "threshold cointegration" as the benchmark. The essential feature of this approach is to allow for regime switching in the transmission of prices, such that the correction of deviations from the long-run equilibrium displays threshold behavior. Applications of threshold cointegration to price transmission include Goodwin and Piggot (2001), Ben-Kaabia and Gil (2007), and Balcombe et al. (2007). Recent developments have featured increasingly sophisticated econometric specifications, such as polynomial fitting, Markov-switching, and smooth transition models (Serra et al., 2006; Ihle et al., 2009; Goodwin et al., 2011, Hahn et al., 2016).

A feature of the threshold autoregressive models of price transmission is that, under certain assumptions, they can recover transfer costs as estimated parameters. More specifically, in the canonical version of this model for two trading points, such parameters identify a "band of inactivity" such that arbitrage activities (e.g., trade) are triggered when price differences tend to move outside this band. This is attractive because the model offers a coherent way of capturing the nonlinearities implied by the presumption of switching regimes (trade or no trade, depending on whether price differences are smaller or greater than transfer costs). The modeling approach also elegantly deals with the fact that, for most empirical applications of price transmission, transfer costs and trade flows are often not observable.

Despite the wide diffusion of threshold autoregressive price transmission models, concerns have been raised from several points of view. One criticism focuses on the fact that price data alone may provide an insufficient basis to make inference about the performance of markets. Specifically, additional information and data on actual transport costs, quantities transacted and trade flows would be especially helpful (Barrett 2001). Another strand of criticism has focused on the econometric challenges of estimating threshold parameters. A broader cautionary perspective recognizes that applying these price transmission models to real-world data, and interpreting estimation results, requires 
a lucid grasp of the process being modeled, that is, “... a wider understanding of the structure and institutions underlying the price data" (Goodwin and Vavra, 2009, p. 10).

This paper contributes to assessing the usefulness of threshold autoregressive price transmission models by reporting the results of a Monte Carlo experiment wherein several performance features of some standard inference procedures are assessed in a context where the data generating process (DGP) is known. Studies in this setting typically focus on the modeler's "estimation problem," wherein one seeks the best procedure to recover the parameters of a model that is held to be true by assumption (e.g., Greb et al. 2013). In the spirit of Goodwin and Vavra's (2009) thoughtful discussion, however, we propose to focus on what may be termed the modeler's "specification problem," whereby a parametric structure is postulated to represent and interpret a real-world setting of interest. As in Fackler and Tastan (2008), we emphasize the need for an explicit consideration of the underlying economic model of price determination. Hence, rather than relying on a reduced-form parameterization, the DGP that we invoke is based on a structural specification in which the notion of price transmission has a clear and explicit economic interpretation.

Specifically, the economic model that generates our data is predicated on the basic competitive model of spatial equilibrium (Takayama and Judge, 1971), but embeds two (related) features that, while plausible attributes of most real world situations, are often neglected in applied work (Fackler and Goodwin, 2001): delivery lags and rational expectations. Within this framework, a primary goal is to explore the empirical relevance of the econometrician's problem, wherein the analyst typically cannot observe data on transfer costs or trade flows while attempting to provide inference on market integration based on econometric methods. We also study the implications of different attributes of transfer costs, as well as the speed of price transmission.

The novelty of our approach, relative to previous work that has evaluated the performance of threshold autoregressive price transmission models, follows from the motivation for our Monte Carlo experiment articulated in the foregoing discussion. Rather than seeking an improved estimation method, we take a standard inferential strategy as given and ask how well it captures the salient attributes of the underlying economic model. The particular 
structure of our DGP is predicated on a two-region equilibrium model, in which trade occurs according to rational expectations and the tradeable product is assumed to be perishable. The inferential strategy that we implement is based on testing for unit-roots and estimating a threshold autoregressive model (or a simpler autoregressive specification) in order to quantify the transfer costs. Furthermore, we explore the robustness of our findings through sensitivity analysis.

The remainder of the paper is organized as follows. The next section presents the theoretical structure of DGP that embeds delivery lags and (rational) price expectations in a two-region spatial equilibrium model. This is followed by parameterization of the model and a discussion of the implied price dynamics. The various simulation scenarios considered are discussed next, along with the inference strategy used to evaluate the modeling approach. This is followed by a presentation of the results of the analysis, and a discussion of the main conclusions.

\section{The DGP: Price Expectations and Spatial Arbitrage}

The data used to evaluate the estimators of interest is generated from a structural representation of a prototypical market where delivery lags give rise to a meaningful role for price expectations to influence arbitrage decisions. The underlying economic environment is that of a competitive model of spatial equilibrium. To capture the essence of the economic forces at work, we focus on the simplest possible structure: a two-region equilibrium model in which trade occurs according to rational expectations and the tradeable product is assumed to be perishable.

Arbitrage entails that prices in two markets linked by trade tend to be equalized as a consequence of agents pursuing profitable trade opportunities. This results in the LOP noted earlier, according to which prices should differ at most by the transfer costs needed to move the goods from one location to the other (except for corner solutions). The transfer costs determine the so-called "inactivity band" within which no adjustments take place. In analytical terms, the arbitrage conditions can be stated as follows:

$\left|P^{A}-P^{B}\right| \geq T$ if $X>0$, 
$\left|P^{A}-P^{B}\right|<T$ if $X=0$,

where $P^{i}$ denotes the price in region $i \in\{A, B\}, T>0$ represents the per-unit transfer costs to ship the good between $A$ and $B$, and $X$ is the quantity shipped between regions.

The foregoing formulation makes it apparent why one should expect threshold effects in price transmission: the equilibrating role of spatial arbitrage (trade) does not come into play when prices differ by less than transfer costs. A variety of threshold cointegration specifications have been proposed for the econometric analysis of price transmission. Because analyzing all of them is not workable, here we focus our attention on the BandTVECM proposed by Balke and Fomby (1997, p. 631), arguably the most popular and intuitive specification to model the arbitrage conditions (1)-(2):

$z_{t}=\left\{\begin{array}{lll}\theta(1-\rho)+\rho z_{t-1}+e_{t} & \text { if } & z_{t-1}>\theta, \\ z_{t-1}+e_{t} & \text { if } & \left|z_{t-1}\right| \leq \theta, \\ -\theta(1-\rho)+\rho z_{t-1}+e_{t} & \text { if } & z_{t-1}<-\theta .\end{array}\right.$

In the above expression, $z_{t} \equiv P_{t}^{A}-P_{t}^{B}$ is the spatial price differential, parameter $\theta$ determines the equilibrium band $[-\theta, \theta]$ to which variable $z$ tends to return over time, $(1-\rho)$ reflects the speed of price transmission, and $e_{t}$ is an independently and identically distributed (i.i.d.) $N\left(0, \sigma^{2}\right)$ error. Within the so-called "inactivity band" $[-\theta, \theta], z$ follows a random walk without drift. If $\theta=0$, the inactivity band disappears and the price differential follows a process with unconditional mean equal to zero and autocorrelation equal to $\rho \in(0,1)$. Parameter $\rho$ is inversely related to the speed at which $z$ tends to revert to the band. When $\rho \rightarrow$ 1 , the speed of price transmission equals zero, and the inactivity band cannot be identified because the price differential behaves as a random walk everywhere. ${ }^{1}$

Based on competitive spatial equilibrium theory, spatial price differentials $z_{t}$ that exceed the inactivity band are corrected toward the edges of the band. Within the band, price differentials are not large enough to trigger arbitrage, and behave like a random walk. In terms of trading activities, three regimes can be distinguished based on the value of the price differential $z$, namely: (a) the price differential is larger than the threshold $\theta$, so that trade

\footnotetext{
${ }^{1}$ An earlier model assuming a stationary price differential inside the band of inaction was developed by Spiller and Woods (1988a, 1988b). Such assumption is a likely reason why their model has not been widely adopted, as it seems less realistic than the nonstationary no-trade price differential that characterizes the Band-TVECM (3).
} 
occurs from $B$ to $A$; (b) the price differential is smaller in absolute value than the threshold, implying no trade; and (c) the price differential is smaller than the negative of the threshold (i.e., $P_{t}^{B}-P_{t}^{A}>\theta$ ), with trade taking place from $A$ to $B$.

The performance of the econometric formulation of price transmission in (3), however, is bound to depend on the specific structure that is generating the prices $P_{t}^{i}$. In the experiment reported in this paper, we assume a simple but explicit economic model of price determination with stochastic supply and demand conditions in each market, in a setting where agents' expectations play a meaningful role.

Specifically, each region contains a terminal market where, in each period, price reflects the equilibrium between local demand and total shipments to that market from both regions. In each region production has to be pooled and shipped to either or both of the terminal market locations, and this basic marketing stage takes some time. We abstract from storage and assume that the product is perishable (e.g., vegetables) and must be consumed once it reaches the terminal markets. The two regions are labeled $A$ and $B$, and the sequence of events is as follows: at the beginning of period $t$ the amount of production $S_{t}^{i}$ is realized in region $i \in\{A, B\}$ and becomes available for shipment to the terminal markets of either/both regions. The transportation/marketing stage takes some time, and so shipping decisions have to be based on the agents' expectation of the equilibrium price that will emerge in the terminal markets later in the period, when consumption will take place. Given the assumption that the product is perishable and storage is not possible, the total amount shipped to either terminal location in period $t$ is available to satisfy demand only in this period. Figure 1 illustrates the presumed timeline, where we adopt the convention of labeling the period by its beginning date.

Let $x_{t}^{i j} \in[0,1]$ denote the share of output $S_{t}^{i}$ shipped to market $j$, for $i, j \in\{A, B\}$. The fact that shipments from a region cannot exceed total availability in that region is expressed as the constraint

$S_{t}^{i} \geq x_{t}^{i i} S_{t}^{i}+x_{t}^{i j} S_{t}^{i}$

for $i \neq j$ and $i, j \in\{A, B\}$. Similarly, consumption in region $i \in\{A, B\}$ in period $t$, labeled $C_{t}^{i}$, cannot exceed the amount available, in other words, 
$C_{t}^{i} \leq x_{t}^{i i} S_{t}^{i}+x_{t}^{j i} S_{t}^{j}$,

for $j \neq i$ and $j \in\{A, B\}$.

As noted, immediately after output $S_{t}^{i}$ is obtained, economic agents decide how much to ship to regions $A$ or $B$, a decision that is based on the expected gains (given the stochastic elements of the system to be discussed shortly) after paying for transfer costs. Let $T_{t}^{i j} \geq 0$ denote the transfer cost required to ship one unit of product from region $i$ to region $j$ in period $t$. Transfer costs may change from period to period, but are known to decision makers at the time of shipping. The cost of shipping between regions is strictly positive $\left(T_{t}^{i j}>0, i \neq j\right)$. Furthermore, we maintain the assumption that it is costlier to ship the good to the other region than to the terminal market of the own region (i.e., $T_{t}^{i j}>T_{t}^{i i}, i \neq j$ ); thus, without further loss of generality, we set $T_{t}^{i i}=0, \forall i, t$. Given that the product is perishable, and together with regularity conditions on demand (to be detailed below), it will always be the case that in each period: ( $a$ ) some of each region's supply is always shipped to the own market (i.e., $x_{t}^{i i}>0$ for $\left.i \in\{A, B\}\right)$; (b) the entire supply in each region is shipped (i.e., expression (4) holds as an equality); and (c) in each market the total shipments arriving from both regions will be consumed (i.e., expression (5) holds as an equality). Condition (a) implies that $x_{t}^{i j} \in[0,1)$ for $i \neq j$, and condition $(b)$ means that $x_{t}^{i i}+x_{t}^{i j}=1, \quad i, j \in\{A, B\}$.

In a competitive setting where individual agents are atomistic and make shipping decisions so as to maximize expected profits conditional on their information at the time of shipment, in equilibrium the shares shipped to the farthest consumption region $\left(\bar{x}_{t}^{A B}\right.$ and $\bar{x}_{t}^{B A}$ ) must exhaust ex ante arbitrage opportunities, in other words, they must simultaneously satisfy the following conditions:

$$
\begin{aligned}
& E_{t}\left(\bar{P}_{t}^{B}\right)-T_{t}^{A B}-E_{t}\left(\bar{P}_{t}^{A}\right) \leq 0, \bar{x}_{t}^{A B} \geq 0,\left[E_{t}\left(\bar{P}_{t}^{B}\right)-T_{t}^{A B}-E_{t}\left(\bar{P}_{t}^{A}\right)\right] \bar{x}_{t}^{A B}=0, \\
& E_{t}\left(\bar{P}_{t}^{A}\right)-T_{t}^{B A}-E_{t}\left(\bar{P}_{t}^{B}\right) \leq 0, \bar{x}_{t}^{B A} \geq 0,\left[E_{t}\left(\bar{P}_{t}^{A}\right)-T_{t}^{B A}-E_{t}\left(\bar{P}_{t}^{B}\right)\right] \bar{x}_{t}^{B A}=0,
\end{aligned}
$$

where the overbar denotes equilibrium values and $E_{t}(\cdot) \equiv E\left(\cdot \mid \Omega_{t}\right)$, (i.e., expectations are rational and conditional on the information set $\Omega_{t}$ at the time of shipping). This information set includes all fixed parameters of the model and the values of all random variables that are realized before the time when shipping decisions are made (more details below). 


\subsection{On the Generality of the DGP Structure: Discussion}

The proposed structure of the DGP is admittedly simple. It does not incorporate many real-world features, such as the possibility of storage and/or the existence of trade across many regions. This is a deliberate choice that is meant to make the outcome of our analysis crisper and easier to interpret. If the question of interest is whether a given econometric procedure can uncover certain properties of a DGP, then making the latter arbitrarily complex can only increase the likelihood of a negative answer. Conversely, if one finds that a given procedure performs poorly in a simple setting, the presumption that it would do better in more complex cases is not tenable.

To elaborate further on the advantages of the postulated DGP structure, note that the typical empirical approach consists of employing historical price series to infer transfer costs across regions. Thus, the empirical analysis of a model consisting of two regions relies on two observed price series (one for each region) to recover one transfer cost. If instead one were to analyze spatial equilibrium among many regions, the number of price series would increase linearly but the number of unknown objects would increase quadratically (e.g., for $n$ regions one would use $n$ observed price series to infer $[n(n-$ 1)/2] transfer costs). Quite clearly, adding regions to the analysis can only exacerbate the problem of identifying transfer costs from the observed price data.

Explicitly allowing for storage decisions would similarly introduce nontrivial complexities (Coleman, 2009a). To the best of our knowledge there is no study showing how to extend the standard storage model (Wright and Williams, 1989) to the case where the endogenously-determined equilibrium prices have a unit root, as required by our analysis. For instance, the numerical solution of the standard storage model provided by Miranda and Fackler (2002, pp. 215-217 and 298-301) deals with a setup that yields stationary prices. Nonetheless, we can conjecture some likely effects of storage on price behavior. The first impact is greater autocorrelation, due to intertemporal arbitrage that links the current price with the expected next-period price via storage. The second impact is smaller price changes in response to exogenous (e.g., weather) shocks, as the addition of the demand for stocks makes total demand more elastic. Hence, even though no storage 
is involved in the proposed DGP, the "Stochastic Supply with High Autocorrelation" and "High Demand Elasticity" scenarios discussed later (which, respectively, yield more autocorrelated prices and more subdued responses to exogenous shocks) may provide valuable insights about the possible impact of introducing storage on inference.

To anticipate some of our findings, results will show that transfer costs are poorly estimated from price data for simplest scenario of $n=2$ regions and no storage. Hence, one can safely conclude that transfer costs would also be poorly estimated from price data for more complex scenarios with $n>2$ regions and/or incorporating storage. In short, increasing the complexity of the model can only exacerbate the (lack of) identification problems that we find characterizes the simplest two-region trade model.

\section{Parameterization and Price Dynamics}

To make this framework operational we need to specify demand and supply conditions. Demand in each region is assumed to be isoelastic, so that the inverse demand functions are written as

$$
P_{t}^{i}=\delta_{t}^{i}\left(C_{t}^{i}\right)^{-1 / \varepsilon_{i}},
$$

where $P_{t}^{i}$ is the price in region $i$ in period $t, \delta_{t}^{i}>0$ is a demand scaling factor defining the market size, and $\varepsilon_{i}$ is the own-price elasticity of demand. With this demand parameterization, consumers' marginal willingness to pay is bounded away from zero $\left(P_{t}^{i}>0\right.$ as long as $C_{t}^{i}<$ $\infty)$, implying that total shipments to each region will be consumed. Together with equations (4) to (6), this implies that equilibrium prices in the two markets are determined along the demand curves, given the quantities shipped to each market in equilibrium:

$$
\begin{aligned}
& \bar{P}_{t}^{A}=\delta_{t}^{A}\left[\left(1-\bar{x}_{t}^{A B}\right) S_{t}^{A}+\bar{x}_{t}^{B A} S_{t}^{B}\right]^{-1 / \varepsilon_{A}}, \\
& \bar{P}_{t}^{B}=\delta_{t}^{B}\left[\bar{x}_{t}^{A B} S_{t}^{A}+\left(1-\bar{x}_{t}^{B A}\right) S_{t}^{B}\right]^{-1 / \varepsilon_{B}} .
\end{aligned}
$$

From the complementarity slackness conditions in (7a) and (7b), it follows that: $(a)$ the expected spatial price differential is exactly equal to the transfer cost when there is a positive shipment between regions, and $(b)$ between-region shipments are equal to zero when the expected price differential is strictly smaller than the transfer cost. Given the specific form of 
the assumed demand functions, the expected price differentials cannot exceed the relevant transfer cost between the regions.

In addition to the role of arbitrage, the dynamic behavior of prices in the two markets will depend on the dynamic properties of the exogenous shocks to supply and demand, which we specify as follows. Production in region $i$ is assumed to follow the (covariance) stationary random process

$\ln \left(S_{t}^{i}\right)=\mu_{i}+\gamma_{i} \ln \left(S_{t-1}^{i}\right)+v_{t}^{i}$,

where $\mu_{i}$ is a scalar that defines the long-term mean supply, $\gamma_{i} \in[0,1)$ is another scalar that determines the level of autocorrelation in supply, and $v_{t}^{i}$ is an i.i.d. $N\left(-0.5 \psi_{i}^{2}, \psi_{i}^{2}\right)$ random shock. Under the assumed distribution for $v_{t}^{i}$, the random variable $\exp \left(v_{t}^{i}\right)$ is $\log$ normally distributed, with mean equal to 1 and variance equal to $\left[\exp \left(\psi_{i}^{2}\right)-1\right] .^{2}$

Because supply is stationary by construction, to generate prices that are $I(1)$ (i.e., integrated of order one), demand (8) is assumed to be subjected to exogenous $I(1)$ shocks: $\ln \left(\delta_{t}^{i}\right)=\ln \left(\delta_{t-1}^{i}\right)+u_{t}^{i}$,

where $u_{t}^{i}$ is an i.i.d. $N\left(-0.5 \xi_{i}^{2}, \xi_{i}^{2}\right)$ random shock. Given process (11), and given the equilibrium quantity shipments $\bar{x}_{t}^{i j}$, the equilibrium price processes (9a) and (9b) can be written as

$$
\begin{aligned}
& \bar{P}_{t}^{A}=\exp \left(u_{t}^{A}\right) \delta_{t-1}^{A}\left[\left(1-\bar{x}_{t}^{A B}\right) S_{t}^{A}+\bar{x}_{t}^{B A} S_{t}^{B}\right]^{-1 / \varepsilon_{A}}, \\
& \bar{P}_{t}^{B}=\exp \left(u_{t}^{B}\right) \delta_{t-1}^{B}\left[\bar{x}_{t}^{A B} S_{t}^{A}+\left(1-\bar{x}_{t}^{B A}\right) S_{t}^{B}\right]^{-1 / \varepsilon_{B}} .
\end{aligned}
$$

By construction, price series in both regions are $I(1)$ and exhibit threshold cointegration.

Consistent with the timeline illustrated in Figure 1, the realized values of the random variables $u_{t}^{i}$ are not part of the information set $\Omega_{t}$ of the conditional expectation $E\left(\cdot \mid \Omega_{t}\right)$ introduced earlier (i.e., shipping decisions are made without knowing the demand shock that

\footnotetext{
${ }^{2}$ Therefore, the conditional mean and variance of $S_{t}^{i}$ are respectively $E_{t}\left(S_{t}^{i}\right)=e^{\mu_{i}}\left(S_{t-1}^{i}\right)^{\gamma_{i}}$ and $\operatorname{Var}_{t}\left(S_{t}^{i}\right)=\left(e^{\psi_{i}^{2}}-1\right)\left[e^{\mu_{i}}\left(S_{t-1}^{i}\right)^{\gamma_{i}}\right]^{2}$, whereas the unconditional mean and variance are $E\left(S_{t}^{i}\right)=$ $\exp \left[\mu_{i} /\left(1-\gamma_{i}\right)-0.5 \gamma_{i} \psi_{i}^{2} /\left(1-\gamma_{i}^{2}\right)\right]$ and $\operatorname{Var}\left(S_{t}^{i}\right)=\left\{\exp \left[\psi_{i}^{2} /\left(1-\gamma_{i}^{2}\right)\right]-1\right\} \exp \left[2 \mu_{i} /\left(1-\gamma_{i}\right)-\gamma_{i} \psi_{i}^{2}\right.$ $\left./\left(1-\gamma_{i}^{2}\right)\right]$, respectively.
} 
will be realized in the terminal markets). That is, if $\Omega_{0}$ denotes the set of all fixed parameters of the model, then $\Omega_{t}=\Omega_{t-1} \bigcup\left\{u_{t-1}^{A}, u_{t-1}^{B}, v_{t}^{A}, v_{t}^{B}\right\}, \forall t>0$.

\section{Simulation Scenarios}

The purpose of the proposed economic model is to provide a transparent framework to to assess the inferences based on threshold cointegration about the true economic structure. structure. To this end, we use the model to simulate data and examine the performance of threshold cointegration inferences for alternative scenarios. The scenarios under study consist consist of specific parameterizations of the underlying economic model, aimed at obtaining simulated data representative of typical time series observations available to econometricians when conducting price analysis. For each scenario, we simulate 1,000 samples (i.e., sets of time series), each of them comprising either 260 or 520 observations for each of the variables analyzed. The design of the simulations and information about the numerical procedures used to solve the model are provided in the online appendix.

\subsection{Transfer Costs}

A drawback encountered when performing econometric analyses of price transmission is that transfer costs are typically not observable, and usually assumed to be constant or simple functions of time. However, such a simplification might hinder the study of price dynamics because in reality transfer costs may change over time.

In order to understand the empirical relevance of transfer costs, we simulated the model under three alternative assumptions, namely, $(a)$ fixed per-unit transfer costs, $(b)$ exogenous time-varying per-unit transfer costs, and $(c)$ endogenous time-varying per-unit transfer costs. In all instances, it is assumed that transfer costs are known to decision-makers at the time of making shipment decisions, but unknown to the econometrician.

The case of fixed per-unit transfer costs, designated "fixed transfer costs" for simplicity, assumes that $T_{t}^{i j}=T^{i j}, \forall t$. The case of exogenous time-varying per-unit transfer costs is obtained by drawing i.i.d. values of $T_{t}^{i j}$ from a beta probability distribution. To simplify the presentation, this case is labeled "stochastic transfer costs" in the remainder of the study. 
Finally, we consider a scenario with endogenous time-varying per-unit transfer costs, or "endogenous transfer costs" for short. International trade studies provide a variety of perspectives on how such transfer costs can be modeled (Behrens and Picard, 2011), but have consistently found that endogenous freight rates respond to trade imbalances (best exemplified, perhaps, by the so-called "backhaul problem"). Thus, we postulate that larger shipment volumes would need to bid away transportation resources from other uses, thereby increasing the unit transfer cost. Hence, for this case per-unit transfer costs are represented by

$T_{t}^{i j}=\tau_{0}+\tau_{1} x_{t}^{i j} S_{t}^{i}$,

where $\tau_{0}$ and $\tau_{1}$ are strictly positive parameters. Unlike the cases of fixed or stochastic transfer costs, endogenous transfer costs imply that the supply of transfer services is not infinitely elastic. Importantly, per-unit transfer costs are endogenous in equilibrium, because the equilibrium share of output shipped $\bar{x}_{t}^{i j}$ that determines $T_{t}^{i j}$ must simultaneously solve the no-arbitrage conditions (7a) and (7b).

\subsection{Parameter Values}

The parameterization adopted for the baseline scenario consists of 520 observations per sample, fixed and symmetric transfer costs with $T_{t}^{i j}=0.05$, a constant and unitary supply in each region $\left(\mu_{i}=\gamma_{i}=\psi_{i}=0\right)$, inelastic demand functions with $\varepsilon_{i}=0.7$, and demand shocks with a variance of $\xi_{i}^{2}=0.00120$. The latter value is the weekly equivalent of a $25 \%$ annual price volatility under autarky, which is a representative volatility for many agricultural commodities (FAO, 2004 p. 51; Gilbert, 2006 p. 51). ${ }^{3}$ This means that the simulations are aimed at mimicking samples of weekly time series observations. Thus, in the case of the baseline, each sample (520 observations) represents ten years of data.

The baseline transfer cost value of $T_{t}^{i j}=0.05$ was determined by calibration. It was obtained by simulating the model so that approximately half of the spatial price differential observations fall inside the transfer cost band (i.e., $\operatorname{Prob}(|z t| \leq 0.05)=0.5$ ),

\footnotetext{
${ }^{3}$ To see this, note that an annual variance of $(0.25)^{2}$ is equal to a weekly variance of $(0.25)^{2} / 52=0.00120$.
} 
and the other half are evenly distributed above and below such band (i.e., $\operatorname{Prob}\left(z_{t}>0.05\right)=$ $\left.\operatorname{Prob}\left(z_{t}<-0.05\right)=0.25\right)$. This was done to ensure a sufficiently large number of observations pertaining to each price differential regime to facilitate their identification. That is, if anything, the baseline simulated series are slanted in favor of identification.

The first four columns of Table 1 show the parameterizations of the alternative scenarios analyzed relative to the baseline. The "high fixed transfer cost" scenario is aimed at uncovering the impact of higher fixed transfer costs. The "stochastic transfer cost" and "high stochastic transfer cost" scenarios are the stochastic counterparts of the baseline and the high fixed transfer cost scenarios. Both of the stochastic transfer cost scenarios assume a fourparameter symmetric beta probability distribution with a coefficient of variation equal to $10 \%$, and a lower bound on the transfer cost equal to half of the mean. The "endogenous transfer cost" scenario corresponds to the situation where transfer costs are modeled as in equation (13), with $\tau_{0}=0.05$ and $\tau_{1}=0.26$. Setting $\tau_{0}=0.05$ ensures that trade under "endogenous transfer cost" occurs if and only if trade in the baseline occurs. Parameter $\tau_{1}=$ 0.26 was set by calibration, so that the unconditional mean transfer cost is approximately the average of the transfer costs in the baseline and the "high transfer cost" scenarios.

The "small sample" scenario is characterized by simulated samples with half of the observations assumed for the baseline, each of them representing five years of weekly data. The "high demand elasticity" scenario imposes elastic rather than inelastic demand in both regions, whereas the "different demand elasticities" scenario assumes that demand is inelastic in region $A$ and elastic in region $B$. Finally, the "stochastic supply" scenarios with "low autocorrelation" and "high autocorrelation" are generated by setting, respectively, $\left[\gamma_{i}, \mu_{i}, \psi_{i}^{2}\right]$ $=[0.2,0.00485,0.0582]$ and $\left[\gamma_{i}, \mu_{i}, \psi_{i}^{2}\right]=[0.9,0.002728,0.011519]$ in the production process (10). Both parameterizations imply the same unconditional expected output as in the baseline, and an unconditional coefficient of variation equal to $\left[\operatorname{Var}\left(S_{t}^{i}\right)\right]^{0.5} / E\left(S_{t}^{i}\right)=25 \%$. However, the weekly autocorrelations are respectively $\gamma_{i}=0.2$ and $\gamma_{i}=0.9$ for the stochastic supply scenarios with "low" and "high" autocorrelation. 


\section{Inference Strategy}

The estimation strategy that we evaluate is aimed at inferring aspects of the true DGP from the simulated data. The procedure consists of two main tasks. The first one is classifying each sample according to the inferred number of spatial price differential $z_{t}$ regimes comprised in it. The second task consists of estimating each sample's DGP parameters, based on the results from the first task.

\subsection{Classification of Samples According to the Number of Spatial Price Differential Regimes}

The strategy to infer the number of $z_{t}$ regimes in each sample is summarized in Figure 2. Following standard practice, the first step consists of conducting an augmented DickeyFuller (ADF) unit root test (Dickey and Fuller, 1979) on each sample's individual price series, followed by an ADF unit root test on the spatial price differential. ${ }^{4}$ The ADF test assumes $I(1)$ under the null hypothesis. The sample is excluded from further consideration if the null of a unit root is rejected for $P_{t}^{A}$ or $P_{t}^{B}$, as cointegration requires both series to be $I(1)$.

The samples that are kept but fail to reject the ADF test null of a unit root for $z_{t}$ are subjected to a Seo test of the null hypothesis of linear no cointegration (Seo, 2006). We proceeded in this manner because the ADF test has much lower power than the Seo test against the alternative hypothesis of threshold cointegration (Seo, 2006), and therefore might incorrectly fail to reject the null. No additional tests are performed on samples that fail to reject Seo's null, as they are inferred to consist entirely of $I(1)$ spatial price differentials. In other words, such samples are inferred to only contain observations pertaining to a single $z_{t}$ regime, consisting of "within band" realizations.

All samples for which the null that $z_{t}$ is $I(1)$ is rejected are assumed to consist of $z t$ observations that belong to at least one $I(0)$ regime. That is, such samples are taken to

\footnotetext{
${ }^{4}$ Even though individual price series are $I(1)$ and the spatial price differential $z_{t}$ is $I(0)$ by construction, in a particular sample any $P_{t}^{A}, P_{t}^{B}$, and $z_{t}$ could be inferred to be $I(0)$ or $I(1)$. However, for a sufficiently large sample with frequent enough spatial arbitrage, one would most likely infer $P_{t}^{A}, P_{t}^{B}$, and $z_{t}$ to be $I(1), I(1)$, and $I(0)$, respectively.
} 
have some $z t$ realizations outside the no-arbitrage band. To determine whether a particular sample contains $z_{t}$ realizations for a single regime (i.e., all $z_{t}$ s are either below or above the the band), two regimes (i.e., all $z_{t}$ s are either below and within the band, or above and within within the band), or all three regimes, we apply Hansen's sequential testing procedure (Hansen, 1999). Hansen's $F_{12}\left(F_{13}, F_{23}\right)$ test postulates a null hypothesis of one (one, two) regime(s) versus an alternative of two (three, three) regimes. Hansen's $F_{12}$ test is conducted conducted first. If $F_{12}$ 's null is rejected, favoring two regimes rather than one, the sample is subjected to the $F_{23}$ test. In this manner, rejecting (failing to reject) $F_{23}$ 's null allows us to conclude that the sample contains $z_{t}$ observations pertaining to three (two) regimes. If $F_{12}$ 's null is not rejected, the $F_{13}$ test is conducted to discriminate between samples involving one and three regimes. We infer that the sample comprises observations for three regimes if $F_{13}$ 's null is rejected, and for only one regime otherwise.

The ADF test was performed using the "adftest" function in the MATLAB program. The tsDyn package (Stigler, 2013) written in the R program was used to conduct Seo's and Hansen's tests. The trimming for the tests was set at $10 \%$ (i.e., each regime was assumed to comprise at least $10 \%$ of the observations in any of the tested samples).

\subsection{Estimation of Transfer Costs and Speed of Price Transmission for Each Sample}

Once it has been determined whether a sample comprises one $I(0)$, two, or three price differential regimes, one can proceed to estimate its corresponding transfer costs and speed of price transmission. In the case of samples inferred to have one $I(0) z_{t}$ regime, the outer equations in expression (3) imply that transfer costs can be estimated by running the unrestricted autoregression

$z_{t}=\alpha+\rho z_{t-1}+e_{t}$

The estimated speed of price transmission is $(1-\hat{\rho})$, and the transfer cost estimate is recovered as $|\hat{\alpha} /(1-\hat{\rho})|$, where hats represent the respective parameter estimates.

For samples inferred to comprise two $z t$ regimes, the econometric model consists of a system of two equations representing the middle and one of the outer regimes in expression (3). Similarly, samples inferred to have three $z_{t}$ regimes are assumed to span all of the three 
regimes. All models are estimated by concentrating the likelihood function on the threshold $\theta$ (Hansen and Seo, 2002). Succinctly, we set a $10 \%$ trim and perform a grid search over the potential threshold values. For each threshold value $\theta_{i}$ on the grid, we obtain the concentrated likelihood $L\left(\theta_{i}\right)$ (i.e., the value of the likelihood function maximized with respect to other parameters of the model). The estimated transfer cost $\hat{\theta}$ is the value $\theta_{i}$ that results in the largest value for $L(\theta)$ over the grid.

\section{Results}

Table 1 summarizes the features of the various parameterizations of the scenarios analyzed, as well as the percentages of observations belonging to each price differential regime and to each trading regime. As explained earlier, transfer costs in the baseline scenario have been calibrated so that observations on price differentials $z t$ are about evenly distributed inside and outside the band of transfer costs. Even though almost half of the observations on price differentials are inside the band, only $6 \%$ of the observations involve no trade. This seemingly counterintuitive result is actually an important feature of the problem at hand. Recall that the arbitrage conditions in (7) depend on expected prices, and they imply that it is the expected price differential for any observation involving positive trade that must be on the boundary of the transfer cost band. Realized prices differ from expected prices by the unanticipated realized shock. In fact, conditional on the equilibrium trade flows $\bar{x}_{t}^{i j}$, the three regimes of the DGP can be represented as follows $z_{t}=\left\{\begin{array}{lll}\theta+e_{t} & \text { if } & \bar{x}_{t}>0, \\ z_{t-1}+e_{t} & \text { if } & \bar{x}_{t}=0, \\ -\theta+e_{t} & \text { if } & \bar{x}_{t}<0,\end{array}\right.$

where $\bar{x}_{t} \equiv \bar{x}_{t}^{A B}-\bar{x}_{t}^{B A}$. Hence, actual price differentials when trade occurs fall outside the band with about $50 \%$ probability. Thus, the $94 \%$ of observations where trade occurs imply about $47 \%$ of realized price differentials outside the transfer cost band. More generally it is worth noting that, with the explicit structural DGP that we postulated, realized price differentials outside of the band are fully consistent with equilibrium and arbitrage. 
Except for the scenarios with large transfer costs, the percentages of observations in different price differential regimes are similar across scenarios. The same is true regarding the percentages of observations in different trading regimes. As expected, scenarios with larger transfer costs yield larger percentages of observations inside the transfer cost band and involving no trade. Importantly, however, all of the scenarios include a relatively large percentage of observations for each of the price differential regimes. This implies that, if anything, the simulated data unduly favor the identification of regimes.

Results for the baseline scenario are discussed in greater depth in the next subsections. Results for the alternative scenarios are largely consistent with the baseline results; hence, in the interest of space, they are reported and discussed in the online appendix.

\subsection{Baseline Scenario: Inference about Price Differential Regimes}

Results regarding inferences on the number of price differential regimes in each sample are reported in Table 2. Column totals show that 198 out of the 1,000 samples contain price differentials that are inside and below or above the transfer cost band (i.e., belong to two regimes), and that the other 802 samples comprise price differentials inside, below, and above the band (i.e., belong to three regimes). In contrast, the inference procedure yields 207 tworegime samples and only 104 three-regime samples.

There are several factors explaining the striking differences between the true and the inferred number of regimes. First, $10.4 \%$ of the samples are incorrectly inferred to involve at least one stationary price series. Such a percentage is somewhat large given the $5 \%$ significance level adopted for the Dickey-Fuller tests. Overrejection arises from using price levels rather than price logarithms to perform the tests, as tests conducted in logarithms yield percentages of unit-root rejections consistent with the $5 \%$ significance level. ${ }^{5}$

\footnotetext{
${ }^{5}$ Most practitioners use prices in logarithms when defining price differentials. However, as shown in the theoretical model section, consistency with trade models requires that price differentials in the empirical specification be constructed using price levels, as opposed to logarithms. Price levels lead to overrejection at the first of the estimation procedure, but they most definitely favor identification at the following stages, because in the true model the no-arbitrage restriction involves price levels.
} 
Second, $24.0 \%$ of the samples are incorrectly categorized as having price differentials which are all inside the transfer cost band, because they are inferred to consist only of cointegrated non-stationary prices. The flow chart in Figure 2 reveals that both the Fuller test and the Seo test are the sources of these inferential errors. Importantly, if Table 2 understates the actual number of incorrect inferences, because the $6.5 \%$ of the samples that failed the numerical computation of the Seo test were assumed to have cointegrated prices to favor the odds of obtaining correct inferences.

Third, $34.5 \%$ of the samples were erroneously inferred to consist of cointegrated price differentials in only one regime (i.e., price differentials either only above or only below the transfer cost band). This inferential mistake accounts for the largest number of misclassifications, and is attributable to Hansen's $F_{12}$ and $F_{13}$ tests (see Figure 2).

The final major source of faulty inferences is the large number (190) of three-regime samples misclassified as having only two regimes. This error is worth noting because the similarity between the inferred and true numbers of two-regime samples (207 vs. 198) might be misleading: in fact, only 17 out of the 207 samples inferred to have only two regimes actually do so. According to Figure 2, these inferential mistakes arise from Hansen's $F_{13}$ and $F_{23}$ tests.

Before turning to the estimated transfer costs, it is worth emphasizing the poor performance of the Seo test, especially given the heavy computational efforts it requires. In the case of the tsDyn package in $\mathrm{R}$, conducting the Seo test on a single sample took about 50 times as long as performing Hansen's $F_{12}$ and $F_{13}$ tests together. Yet, the numerical computation of the Seo test failed in 65 out of the 305 tested samples, and it did not reject the null of no cointegration in any of the other 240 samples. The present results suggest that, from a practitioner's perspective, carrying out the Seo test may simply not be worth the effort.

\subsection{Baseline Scenario: Estimated Transfer Costs}

Summary statistics regarding estimated transfer costs for the baseline scenario are reported in the second column of Table 3. Point estimates of transfer costs based on the 
inferred one-regime samples (mean and median equal to 0.0477 and 0.050 , respectively) are quite similar to the true transfer costs of 0.050 . Interestingly, one-regime estimates have a distribution noticeably skewed to the left, as evidenced by the $5 \%$ and $95 \%$ quantiles of 0.025 and 0.0055 , respectively. Transfer cost estimates based on the inferred two-regime samples exhibit similar characteristics, except for a larger standard deviation and a lesser left skew (5\% and $95 \%$ quantiles of 0.030 and 0.060 , respectively).

Estimates based on the inferred three-regime samples are the worst ones. The mean estimate (0.038) and the median (0.044) are respectively $24 \%$ and $12 \%$ smaller than the true transfer cost (0.050). Further, the estimates exhibit a distribution highly skewed to the left: The $5 \%$ quantile equals only 0.011 , and the $95 \%$ quantile of 0.051 barely includes the true transfer cost. The poor performance of the model at estimating the band parameter is consistent with the Monte Carlo results reported in Greb et al. (2013) (whose DGP, however, is different from the one studied in this paper, as explained earlier).

As discussed in the previous subsection, inferences about the number of regimes are incorrect for most of the samples. Hence, it is of interest to uncover the impact of such errors on the estimation of transfer costs. To this end, the third column in Table 3 provides summary statistics for estimates based on the true number of regimes in each sample. Because none of the samples truly consists of $z_{t}$ observations that belong to one $I(0)$ regime, the corresponding cells are labelled "not applicable."

In the case of transfer costs based on true two-regime samples, point estimates (mean and median equal to 0.0505 and 0.050 , respectively) are almost identical to the true transfer costs. Transfer costs are estimated much more precisely when using true as opposed to inferred two-regime samples, as the standard deviation for the former (equal to 0.0019) is almost one order of magnitude smaller than the standard deviation for the latter (equal to 0.015). Another major difference between the two types of estimates is that the ones based on true two-regime samples have a fairly symmetric distribution, with 5\% and 95\% quantiles of 0.047 and 0.054 , respectively.

The substantially lower quality of the estimates obtained from the inferred two-regime samples should not be surprising, given the inferences shown in Table 2. This table shows 
that only 17 out of the 207 samples inferred to have two regimes truly have two regimes, whereas the other 190 samples actually have three regimes. In other words, 190 out of the 207 inference-based cost estimates are obtained by applying two-regime methods to three-regime samples.

Surprisingly, the transfer cost estimates based on true three-regime samples are of lesser quality than their counterparts based on inferred three-regime samples, as the mean and median exhibit a greater downward bias and the standard deviation is slightly higher. This counterintuitive result is driven by the fact that 103 out of the 104 samples inferred to have three regimes indeed have three regimes, and 699 out of the 802 true three-regime samples are inferred to not contain three regimes (see Table 2). Thus, the inference-based three-regime cost estimates are obtained from the subset of true three-regime samples with the strongest three-regime features.

Given the structural representation in (15) noted earlier, it is clear that if shipment data were available, one could use them not only to determine the number of regimes in a sample, but also to estimate transfer costs. Importantly, shipment data would obviate the need to perform inferences on the number of price differential regimes. In fact, if shipment data were available, transfer costs could be estimated by simply fitting linear regressions like (14) using only the price differentials corresponding to nonzero shipments. Unfortunately, implementing this strategy may not be feasible in most empirical applications, as the econometrician may not be able to obtain shipment data.

\subsection{Baseline Scenario: Estimated Speed of Price Transmission}

The second column of Table 4 reports summary statistics for the estimated speeds of price transmission in the baseline scenario. Point estimates from the inferred one- and two-regime samples are centered around the true value of one (e.g., the respective medians are 0.993 and 1.00), whereas those from the inferred three-regime samples are downwardly biased (mean and median equal to 0.90 and 0.92, respectively). Surprisingly, the one- and two-regime estimates have opposite skewness, the former to the left and the latter to the right. The precision of the estimates worsens substantially as one moves from 
the inferred one-regime samples to the three-regime samples (standard deviations are respectively $0.078,0.17$, and 0.37 for the one-, two-, and three-regime estimates). Overall, the Overall, the three-regime samples yield very noisy estimates, with 5\% and 95\% quantiles equal to 0.25 and 1.52 , respectively.

Summary statistics for speed of price transmission estimates based on the true number of regimes in each sample are shown in the third column of Table 4. Compared to the inferencebased estimates, the ones based on the true regimes are more accurate and, in the case of the three-regime samples, less biased (e.g., the mean is 1.04 and the median equals 0.97 ).

\subsection{Baseline Scenario: Inferences about Individual Observations}

In practice, it is not uncommon to use the estimated transfer costs to make inferences as to whether (i) the individual price differential observations in the sample are within or outside the cost band, or (ii) whether trade occurred at the times corresponding to the sample observations. We provide information about inferences (i) and (ii) for the baseline scenario in Tables 5 and 6, respectively. The reported results correspond to samples inferred to have two and three $z_{t}$ regimes (Panels A and B, respectively), because the empirical threshold cointegration literature concentrates its attention on multi-regime cases.

According to Table 5, inferences about price differentials being within or outside the band are reasonably accurate for samples inferred to have two $z_{t}$ regimes, and less so for their three $z_{t}$ regime counterparts. The results in Panel A indicate that whenever an inferred two-regime sample yields transfer cost estimates considerably different from the true transfer costs, it contains few price differential observations in the interval determined by the estimated and the true transfer costs.

Table 5 reveals that most of the misclassifications consist of price differentials which are actually within the band but are inferred to be outside the band, especially for inferred three regime samples. This finding is consistent with the fact that transfer cost estimates are downwardly biased, especially for inferred three-regime samples (see Table 3).

Studies of price transmission by threshold cointegration analysis are often interested in assessing market integration and market efficiency. Market integration is a concept typically 
associated with the ease of tradability (Baulch, 1997). For our two-region model, an obvious metric to measure the extent of market integration is the probability (or frequency) of trade taking place, which itself depends on the size of transfer costs. If transfer costs were prohibitively high, no trade would ever take place, and segmented equilibria would result wherein each market absorbs its own supply and demand shocks. Conversely, if transfer costs were zero, trade would always take place (demand and supply shocks are fully shared between the regions), and we would say markets are perfectly integrated. As transfer costs increase from zero, the frequency of trade decreases, and hence we can measure market integration by how often the two regions trade with one another.

The results in Table 6 suggest that inferences about trade are quite poor, with the main problem being that "no trade" is inferred much more often than warranted (e.g., $47.5 \%$ vs. $8.8 \%$ for inferred two-regime samples). This result emerges even though, somewhat paradoxically, the model also tends to underestimate the transfer costs (band) parameter, a fact underscoring the relevance of the economic model that we have postulated as the true DGP. The threshold cointegration approach that we have evaluated, therefore, tends to suggest a much lower degree of market integration than is true in the DGP. In light of the previously discussed downwardly biased transfer cost estimates, this finding is seemingly paradoxical; however, it can be easily explained by the structure of the economic model. Whereas the occurrence of trade implies that the expected price differential must be on the boundary of the transfer cost band, it is fully consistent with realized price differentials both inside and outside the band (see discussion of expression (15)).

\section{Conclusions}

The Band-TVECM specification is a popular model to study spatial price transmission. It is rooted in the econometrics of time-series cointegration, and the threshold framework it implements is an appealing way to capture the fact that transfer costs are real impediments to the arbitrage role of trade. In this model, spatial price differences that exceed transfer costs disappear over time, as implied by market 
equilibrium. This appears prima facie consistent with the notion that market equilibrium cannot absorb shocks instantaneously and that time is required for trade to perform its arbitrage role. How well Band-TVECM parameterizations perform at representing the dynamics of spatial market equilibrium, however, has remained an open question.

Previous work on this topic has privileged the study of estimation challenges inherent with this econometric model, while maintaining the validity of the model's parametric structure (e.g., Greb et al., 2013). In this paper we take an alternative tack, and ask how well the Band-TVECM formulation works at capturing the arbitrage conditions of spatial equilibrium. As noted, trade shipments inevitably take time, suggesting that expectations are bound to play a key role in arbitrage decisions. How market equilibrium adjusts to shocks, therefore, will depend on how such expectations affect relevant decisions. Because this is likely to be context-specific, an explicit economic model of price transmission is necessary in order to evaluate the econometric model of interest. Consequently, in this paper we use an explicit economic model — a simple two-region model for a perishable product, a setting where the competitive equilibrium critically depends on agents' expectations- to generate the data that is then used to evaluate the performance of standard inference strategies with the Band-TVECM approach.

We found remarkable differences between the true and the inferred number of price differential regimes in each sample. Even though most samples truly comprise three price differential regimes, the majority of the samples are inferred to contain only one regime. This finding suggests that only a small proportion of real-world price series could end up being analyzed by threshold cointegration. The inferential errors regarding the number of regimes in each sample emerges notwithstanding our reliance on the canonical tests proposed by Dickey and Fuller, Hansen, and Seo. Importantly, the poor performance of the Seo test suggests it may not be worthwhile to conduct it, especially in view of the computational effort that it requires.

Transfer costs estimates based on the inferred three-regime samples were found to be severely downwardly biased. Importantly, they are better than the transfer costs estimated from the true three-regime samples. This counterintuitive result is explained by the fact that 
the Band-TVECM does not exactly match the structure of the economic model underlying the data. Worryingly, it suggests that improved inference regarding the number of regimes in the sample may not lead to better transfer cost estimates.

The speed of price transmission estimated from the inferred tree-regime samples is downwardly biased and has a large standard deviation. The scenario with endogenous transfer costs and the two scenarios with high transfer costs exhibit the largest bias, with mean estimates $30 \%$ to $40 \%$ smaller than the true speed of price transmission.

Inferences about individual observations of price differentials being within or outside the band proved to be reasonably accurate, especially for samples inferred to have two regimes. In contrast, inferences as to whether individual observations involved trade or not were quite poor, with "no trade" being inferred far more often than warranted. The result is seemingly paradoxical, as it suggests that threshold cointegration may mislead the practitioner into underestimating both the magnitude of transfer costs and the extent of market integration. This underscores the importance of the actual economic model, which in our case yields about half of the observations on price differentials outside the transfer costs band, even though trade occurs most of the time.

Based on the tests that most parsimoniously mimic the structure of the underlying trading model, our results indicate that the Band-TVECM typically used to analyze price transmission, while intuitively appealing, fails to capture essential features of the dynamics concerning expectations and trade. Even though it is beyond the scope of the present analysis to examine all of the tests that could be used (e.g., Enders and Granger, 1998; Kapetianos and Shin, 2006), our results suggest that, to the extent that they only rely on price data for inference, they are likely to face the same limitations as the tests used here. As such, our study suggests that results from applying the Band-TVECM should be more strongly qualified, and that it would be valuable to develop threshold cointegration models whose structure is better aligned with the economic fundamentals of trade. 


\section{References}

Ardeni, P.G., 1989. Does the Law of One Price really hold for commodity prices? Amer. J. Agric. Econ. 71, 661-669.

Balcombe, K., Bailey, A., Brooks, J., 2007. Threshold effects in price transmission: The case of Brazilian wheat, maize and soya prices. Amer. J. Agric. Econ. 89, 308-323.

Balke, N.S., Fomby, T.B., 1997. Threshold cointegration. Internat. Econ. Rev. 38, 627-645.

Barrett, C.B., 2001. Measuring integration and efficiency in international agricultural markets. Rev. Agric. Econ. 23, 19-32.

Baulch, B., 1997. Transfer costs, spatial arbitrage, and testing for food market integration. Amer. J. Agric. Econ. 79, 477-487.

Ben-Kaabia, M., Gil, J.M., 2007. Asymmetric price transmission in the Spanish lamb sector. Europ. Rev. Agric. Econ. 34, 53-80.

Behrens, K., Picard, P.M., 2011. Transportation, freight rates, and economic geography. J. Internat. Econ. 85, 280-291.

Coleman, A., 2009a. A model of spatial arbitrage with transport capacity constraints and endogenous transport prices. Amer. J. Agric. Econ. 91, $42-56$.

Coleman, A., 2009b. Storage, slow transport, and the Law of One Price: Theory with evidence from nineteenth-century U.S. corn markets. Rev. Econ. Stat. 91, 332-350.

Dickey, D.A., Fuller, W.A., 1979. Distribution of the estimators for autoregressive time series with a unit root. J. Amer. Stat. Assoc. 74, 427-431.

Enders, W., Granger, C., 1998. Unit-root tests and asymmetric adjustment with an example using the term structure of interest rates. J. Bus. Econ. Stat. 16, 304-311.

Fackler, P.L., Goodwin, B.K., 2001. Spatial price analysis, in B.L. Gardner and G.C. Rausser, eds., Handbook of Agricultural Economics, Volume 1. Elsevier, Amsterdam.

Fackler, P.L., Tastan, H., 2008. Estimating the degree of market integration. Amer. J. Agric. Econ. 90, 69-85.

Food and Agriculture Organization of the United Nations (FAO), 2004. The State of Agricultural Commodity Markets 2004. FAO, Rome. 
García-Germán, S., Bardají, I., Garrido, A., 2016. Evaluating price transmission between global agricultural markets and consumer food price indices in the European Union. Agric. Econ. 47, 59-70.

Gilbert, C.L., 2006. Trends and volatility in agricultural commodity prices, in A. Sarris and D. Hallam, eds., Agricultural Commodity Markets and Trade: New Approaches to Analyzing Market Structure and Instability, Ch. 2. Edward Elgar Publishing, Northampton, MA.

Goodwin, B.K., Holt, M.T., Prestemon, J.P., 2011. North American oriented strand board markets, arbitrage activity, and market price dynamics: A smooth transition approach. Amer. J. Agric. Econ. 93, 993-1014.

Goodwin, B.K., Piggott, N., 2001. Spatial market integration in the presence of threshold effects. Amer. J. Agric. Econ. 83, 302-317.

Goodwin, B.K., Vavra, P., 2009. What can we learn from spatial and vertical price transmission studies? Empirical examples from U.S. meat markets. Courant Research Centre 'Poverty, Equity and Growth' Inaugural Conference, Georg-August-Universität Göttingen, Germany.

Greb, F., von Cramon-Taubadel, S., Krivobokova, T., Munk, A., 2013. The estimation of threshold models in price transmission analysis. Amer. J. Agric. Econ. 95, 900-916.

Hahn, W., Stewart, H., Blayney, D.P., Davis, C.G., 2016. Modeling price transmission between farm and retail prices: A soft switches approach. Agric. Econ. 47, 193-203.

Hansen, B.E., 1999. Testing for linearity. J. Econ. Surveys 13, 551-576.

Hansen, B.E., Seo, B., 2002. Testing for two-regime threshold cointegration in vector errorcorrection models. J. Econometrics 110, 293-318.

Ihle, R., von Cramon-Taubadel, S., Sergiy, Z., 2009. Markov-switching estimation of spatial maize price transmission processes between Tanzania and Kenya. Amer. J. Agric. Econ. 91, 1432-1439.

Kapetianos, G., Shin, Y., 2006. Unit root tests in three-regime SETAR models. Econometrics J. 9, 252-278. 
Miranda, M.J., Fackler, P.L., 2002. Applied Computational Economics and Finance. MIT Press, Cambridge, MA.

Myers, R.J., Jayne, T.S., 2012. Multiple-regime spatial price transmission with an application to maize markets in Southern Africa. Amer. J. Agric. Econ. 94, 174-188.

Seo, M., 2006. Bootstrap testing for the null of no cointegration in a threshold vector error correction model. J. Econometrics 134: 129-150.

Serra, T., Gil, J.M., Goodwin, B.K., 2006. Local polynomial fitting and spatial price relationships: Price transmission in EU pork markets. Europ. Rev. Agric. Econ. 33: 415436.

Shiue, C.H., 2002. Transport costs and the geography of arbitrage in eighteenth-century China. Amer. Econ. Rev. 92, 1406-1419.

Spiller, P.T., Wood, R.O., 1988a. Arbitrage during the dollar-sterling gold standard, 18991908: An econometric approach. J. Polit. Econ. 96, 882-892.

Spiller, P.T., Wood, R.O., 1988b. The estimation of transaction costs in arbitrage models. $J$. Econometrics 39, 309-326.

Stephens, E.C., Mabaya, E., von Cramon-Taubadel, S., Barrett, C., 2011. Spatial price adjustment with and without trade. Oxford Bull. Econ. Stat. 74, 453-469.

Stigler, M., 2013. Threshold cointegration: Overview and implementation in R. Working Paper. Accessed June 2017, available at https://cran.rproject.org/web/packages/tsDyn/vignettes/ThCointOverview.pdf

Takayama, T., Judge, G.G., 1971. Spatial and Temporal Price and Allocation Models. NorthHolland, Amsterdam.

United Nations Conference on Trade and Development, 2013. Review of Maritime Transport 2013. United Nations, New York and Geneva.

Wright, B.D., Williams, J.C., 1989. A theory of negative prices for storage. J. Fut. Markets $\mathbf{9}$, $1-13$. 

Table 2. True and inferred number of samples of different types in the baseline scenario.

\begin{tabular}{|c|c|c|c|c|c|c|}
\hline & & \multicolumn{4}{|c|}{ True Number of $z t$ Regimes in the Sample } & \multirow{3}{*}{$\begin{array}{l}\text { Row } \\
\text { Total }\end{array}$} \\
\hline & & \multicolumn{2}{|c|}{ One } & \multirow[t]{2}{*}{ Two } & \multirow[t]{2}{*}{ Three } & \\
\hline & & $I(1)$ & $I(0)$ & & & \\
\hline \multirow{5}{*}{$\begin{array}{l}\text { Inferred } \\
\text { Number of } z t \\
\text { Regimes in } \\
\text { the Sample }\end{array}$} & $P_{t}^{A}$ or $P_{t}^{B}$ are $I(0)$ & 0 & 0 & 33 & 71 & 104 \\
\hline & One $I(1)$ & 0 & 0 & 127 & 113 & 240 \\
\hline & One $I(0)$ & 0 & 0 & 20 & 325 & 345 \\
\hline & Two & 0 & 0 & 17 & 190 & 207 \\
\hline & Three & 0 & 0 & 1 & 103 & 104 \\
\hline \multicolumn{2}{|l|}{ Column Total } & 0 & 0 & 198 & 802 & 1000 \\
\hline
\end{tabular}

Note: There were 65 samples for which the numerical procedures for the Seo test failed. Consistent with the stated intent of favoring correct inferences, such samples were classified as having cointegrated prices (i.e., it was assumed that for them the Seo test rejected the null of linear no cointegration between $P^{A}$ and $P^{B}$ ). 
Table 3. Estimated transfer costs for the baseline scenario. ${ }^{\mathrm{a}}$

\begin{tabular}{|c|c|c|}
\hline & \multicolumn{2}{|c|}{ Transfer Cost Estimates Based on } \\
\hline & Inferred Sample Types & True Sample Types \\
\hline & $\begin{array}{c}\text { Mean } \\
\text { (Standard Deviation) } \\
{[5 \%, 50 \%, 95 \%] \text { Quantiles }}\end{array}$ & $\begin{array}{c}\text { Mean } \\
\text { (Standard Deviation) } \\
{[5 \%, 50 \%, 95 \%] \text { Quantiles }}\end{array}$ \\
\hline One $I(0) z_{t}$ Regime Samples & $\begin{array}{c}0.0477 \\
(0.0097) \\
{[0.025,0.050,0.055]}\end{array}$ & $\begin{array}{l}\text { Not Applicable } \\
\text { Not Applicable } \\
\text { Not Applicable }\end{array}$ \\
\hline Two $z_{t}$ Regime Samples & $\begin{array}{c}0.048 \\
(0.015) \\
{[0.030,0.049,0.060]}\end{array}$ & $\begin{array}{c}0.0505 \\
(0.0019) \\
{[0.047,0.050,0.054]}\end{array}$ \\
\hline Three $z t$ Regime Samples & $\begin{array}{c}0.038 \\
(0.014) \\
{[0.011,0.044,0.051]}\end{array}$ & $\begin{array}{c}0.031^{\mathrm{b}} \\
(0.015)^{\mathrm{b}} \\
{[0.011,0.029,0.051]^{\mathrm{b}}}\end{array}$ \\
\hline
\end{tabular}


Table 4. Estimated speed of price transmission for the baseline scenario. ${ }^{\text {a }}$

\begin{tabular}{|c|c|c|}
\hline & \multicolumn{2}{|c|}{ Speed of Price Transmission Estimates Based on } \\
\hline & Inferred Sample Types & True Sample Types \\
\hline & $\begin{array}{c}\text { Mean } \\
\text { (Standard Deviation) } \\
{[5 \%, 50 \%, 95 \%] \text { Quantiles }}\end{array}$ & $\begin{array}{c}\text { Mean } \\
\text { (Standard Deviation) } \\
{[5 \%, 50 \%, 95 \%] \text { Quantiles }}\end{array}$ \\
\hline One $I(0) z_{t}$ Regime Samples & $\begin{array}{c}0.981 \\
(0.078) \\
{[0.820,0.993,1.071]}\end{array}$ & $\begin{array}{l}\text { Not Applicable } \\
\text { Not Applicable } \\
\text { Not Applicable }\end{array}$ \\
\hline Two $z_{t}$ Regime Samples & $\begin{array}{c}1.02 \\
(0.17) \\
{[0.80,1.00,1.29]}\end{array}$ & $\begin{array}{c}1.03 \\
(0.11) \\
{[0.82,1.04,1.20]}\end{array}$ \\
\hline Three $z_{t}$ Regime Samples & $\begin{array}{c}0.90 \\
(0.37) \\
{[0.24,0.92,1.52]}\end{array}$ & $\begin{array}{c}1.04^{\mathrm{b}} \\
(0.29)^{\mathrm{b}} \\
{[0.70,0.97,1.60]^{\mathrm{b}}}\end{array}$ \\
\hline
\end{tabular}


Table 5. Percentages of observations in alternative spatial price differential regimes for the baseline scenario.

A. Conditional on samples inferred to have two $z t$ regimes. $^{a}$

\begin{tabular}{lcccc}
\hline & & \multicolumn{2}{c}{ True $_{z t}$ Regime $^{\mathrm{c}}$} & \multirow{2}{*}{ Row Total } \\
\cline { 3 - 4 } & & Within Band & Outside Band & \\
\hline Inferred $z t$ & Within Band & 45.6 & 1.9 & 47.5 \\
Regime $^{\mathrm{b}}$ & Outside Band & 4.7 & 47.8 & 52.5 \\
\hline Column Total & & 50.3 & 49.7 & 100.0 \\
\hline
\end{tabular}

${ }^{\mathrm{a}}$ The table only classifies $20.7 \%$ of the total simulated observations, corresponding to the 207 baseline samples inferred to have two $z_{t}$ regimes.

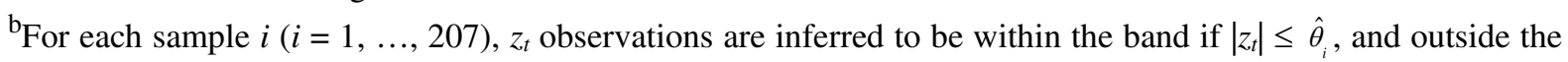
band otherwise, where $\hat{\theta}_{i}$ is the transfer cost estimated using only sample $i$ data.

${ }^{\mathrm{c}}$ The true $z_{t}$ regime is within the band if $\left|z_{t}\right| \leq 0.05$, and is outside the band otherwise.

B. Conditional on samples inferred to have three $z_{t}$ regimes. ${ }^{\mathrm{a}}$

\begin{tabular}{|c|c|c|c|c|}
\hline & & \multicolumn{2}{|c|}{ True $z_{t}$ Regime $^{\mathrm{c}}$} & \multirow[t]{2}{*}{ Row Total } \\
\hline & & Within Band & Outside Band & \\
\hline Inferred $z t$ & Within Band & 40.3 & 0.3 & 40.6 \\
\hline Regime $^{\mathrm{b}}$ & Outside Band & 15.6 & 43.8 & 59.4 \\
\hline Column Total & & 55.9 & 44.1 & 100.0 \\
\hline
\end{tabular}

${ }^{\mathrm{a}}$ The table only classifies $10.4 \%$ of the total simulated observations, corresponding to the 104 baseline samples inferred to have three $z_{t}$ regimes.

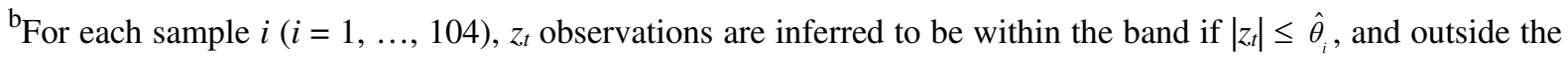
band otherwise, where $\hat{\theta}_{i}$ is the transfer cost estimated using only sample $i$ data.

${ }^{\mathrm{c}}$ The true $z_{t}$ regime is within the band if $\left|z_{t}\right| \leq 0.05$, and is outside the band otherwise. 
Table 6. Percentages of observations in alternative trading regimes for the baseline scenario.

A. Conditional on samples inferred to have two $z_{t}$ regimes. ${ }^{\mathrm{a}}$

\begin{tabular}{lcccc}
\hline & & \multicolumn{2}{c}{ True Trading Regime $^{\mathrm{c}}$} & \multirow{2}{*}{ Row Total } \\
\cline { 3 - 4 } & & No Trade & Trade & \\
\hline \multirow{2}{*}{ Inferred Trading Regime $^{\mathrm{b}}$} & No Trade & 6.5 & 41.0 & 47.5 \\
& Trade & 2.3 & 50.2 & 52.5 \\
\hline \multirow{2}{*}{ Column Total } & & 8.8 & 91.2 & 100.0 \\
\hline
\end{tabular}

${ }^{a}$ The table only classifies $20.7 \%$ of the total simulated observations, corresponding to the 207 baseline samples inferred to have two $z_{t}$ regimes.

${ }^{\mathrm{b}}$ For each sample $i(i=1, \ldots, 207)$, "no trade" is inferred if $\left|z_{t}\right| \leq \hat{\theta}_{i}$, and "trade" is inferred otherwise, where $\hat{\theta}_{i}$ is the transfer cost estimated using only sample $i$ data.

"The true regime is "no trade" if trade did not occur, and "trade" otherwise.

B. Conditional on samples inferred to have three $z_{t}$ regimes. ${ }^{\mathrm{a}}$

\begin{tabular}{lcccc}
\hline & & \multicolumn{2}{c}{ True Trading Regime $^{\mathrm{c}}$} & \multirow{2}{*}{ Row Total } \\
\cline { 3 - 4 } & & No Trade & Trade & \\
\hline \multirow{2}{*}{ Inferred Trading Regime $^{\mathrm{b}}$} & No Trade & 12.9 & 27.7 & 40.6 \\
& Trade & 5.1 & 54.3 & 59.4 \\
\hline \multirow{2}{*}{ Column Total } & & 18.0 & 82.0 & 100.0 \\
\hline
\end{tabular}

${ }^{\mathrm{a}}$ The table only classifies $10.4 \%$ of the total simulated observations, corresponding to the 104 baseline samples inferred to have three $z_{t}$ regimes.

${ }^{b}$ For each sample $i(i=1, \ldots, 104)$, "no trade" is inferred if $\left|z_{t}\right| \leq \hat{\theta}_{i}$, and "trade" is inferred otherwise, where $\hat{\theta}_{i}$ is the transfer cost estimated using only sample $i$ data.

"The true regime is "no trade" if trade did not occur, and "trade" otherwise. 
Figure 1. Sequence of events in period $t$

$\underset{t}{\stackrel{2}{*} \begin{array}{c}\text { Shipping } \\ \text { Pecisions }\end{array}}$


Figure 2. Econometric strategy to classify individual simulated samples

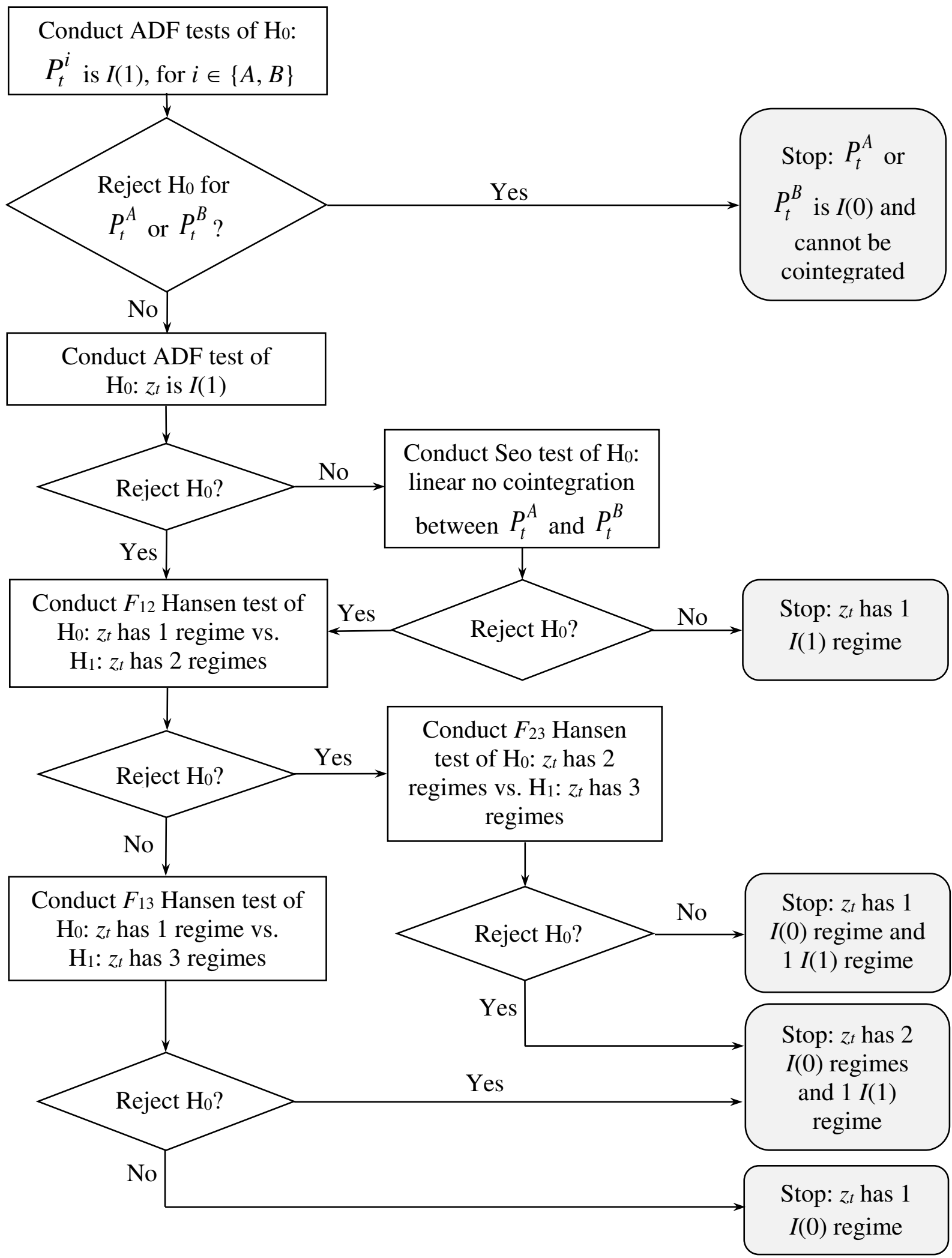


Threshold Cointegration and Spatial Price Transmission when Expectations Matter Sergio H. Lence, GianCarlo Moschini and Fabio Gaetano Santeramo*

\section{Online Appendix}

* Lence is Professor and Marlin Cole Chair of International Agricultural Economics, Department of Economics, Iowa State University. Moschini is Professor and Pioneer Chair in Science and Technology Policy, Department of Economics and CARD, Iowa State University. Santeramo is Ricercatore, University of Foggia, Italy. Senior authorship is not assigned. 


\section{Appendix A: Simulation Design and Numerical Procedures}

The algorithm used to generate the simulated data for each sample under stochastic transfer costs and stochastic output can be summarized as follows:

Step 1. Set initial values $\left\{S_{(0)}^{A}=1, S_{(0)}^{B}=1, \delta_{(0)}^{A}=1, \delta_{(0)}^{B},=1\right\}$.

Step 2. Generate realizations $\left\{v_{(n)}^{A}, v_{(n)}^{B}\right\}$ from their respective distributions.

Step 3. Use $\left\{S_{(n-1)}^{A}, S_{(n-1)}^{B}, v_{(n)}^{A}, v_{(n)}^{B}\right\}$ to obtain $\left\{S_{(n)}^{A}, S_{(n)}^{B}\right\}$, as follows:

$$
S_{(n)}^{i}=\left(S_{(n-1)}^{i}\right)^{\gamma_{i}} \exp \left(\mu_{i}+v_{(n)}^{i}\right)
$$

for $i \in\{A, B\}$.

Step 4. Generate realizations $\left\{T_{(n)}^{A B}, T_{(n)}^{B A}\right\}$ from their respective beta distributions.

Step 5. Use $\left\{S_{(n)}^{A}, S_{(n)}^{B}, \delta_{(n-1)}^{A}, \delta_{(n-1)}^{B}, T_{(n)}^{A B}, T_{(n)}^{B A}\right\}$ to solve numerically for the values $\left\{\bar{x}_{(n)}^{A B}, \bar{x}_{(n)}^{B A}\right\}$ that satisfy simultaneously the following arbitrage conditions

$$
\left\{\begin{array}{l}
E_{(n)}\left(\bar{P}_{(n)}^{B}\right)-T_{(n)}^{A B}-E_{(n)}\left(\bar{P}_{(n)}^{A}\right) \leq 0, \\
1>\bar{x}_{(n)}^{A B} \geq 0, \\
{\left[E_{(n)}\left(\bar{P}_{(n)}^{B}\right)-T_{(n)}^{A B}-E_{(n)}\left(\bar{P}_{(n)}^{A}\right)\right] \bar{x}_{(n)}^{A B}=0,}
\end{array}\right.
$$

$$
\left\{\begin{array}{l}
E_{(n)}\left(\bar{P}_{(n)}^{A}\right)-T_{(n)}^{B A}-E_{n}\left(\bar{P}_{(n)}^{B}\right) \leq 0, \\
1>\bar{x}_{(n)}^{B A} \geq 0, \\
{\left[E_{(n)}\left(\bar{P}_{(n)}^{A}\right)-T_{(n)}^{B A}-E_{(n)}\left(\bar{P}_{(n)}^{B}\right)\right] \bar{x}_{(n)}^{B A}=0,}
\end{array}\right.
$$

where $E_{(n)}\left(\bar{P}_{(n)}^{A}\right) \equiv \delta_{(n-1)}^{A}\left[\left(1-\bar{x}_{(n)}^{A B}\right) S_{(n)}^{A}+\bar{x}_{(n)}^{B A} S_{(n)}^{B}\right]^{-1 / \varepsilon_{A}}$ and $E_{(n)}\left(\bar{P}_{(n)}^{B}\right) \equiv$ $\delta_{(n-1)}^{B}\left[\bar{x}_{(n)}^{A B} S_{(n)}^{A}+\left(1-\bar{x}_{(n)}^{B A}\right) S_{(n)}^{B}\right]^{-1 / \varepsilon_{B}}$.

Step 6. Generate realizations $\left\{u_{(n)}^{A}, u_{(n)}^{B}\right\}$ from their respective distributions.

Step 7. Use $\left\{\delta_{(n-1)}^{A}, \delta_{(n-1)}^{B}, u_{(n)}^{A}, u_{(n)}^{B}\right\}$ to compute $\left\{\delta_{(n)}^{A}, \delta_{(n)}^{B}\right\}$ by means of

$$
\delta_{(n)}^{i}=\delta_{(n-1)}^{i} \exp \left(u_{(n)}^{i}\right)
$$


for $i \in\{A, B\}$.

Step 8. Use $\left\{S_{(n)}^{A}, S_{(n)}^{B}, \bar{x}_{(n)}^{A B}, \bar{x}_{(n)}^{B A}, \delta_{(n)}^{A}, \delta_{(n)}^{B}\right\}$ to calculate $\left\{\bar{P}_{(n)}^{A}, \bar{P}_{(n)}^{B}\right\}$ from

$$
\begin{aligned}
& \text { (A4a) } \bar{P}_{(n)}^{A}=\delta_{(n)}^{A}\left[\left(1-\bar{x}_{(n)}^{A B}\right) S_{(n)}^{A}+\bar{x}_{(n)}^{B A} S_{(n)}^{B}\right]^{-1 / \varepsilon_{A}}, \\
& \text { (A4b) } \bar{P}_{(n)}^{B}=\delta_{(n)}^{B}\left[\bar{x}_{(n)}^{A B} S_{(n)}^{A}+\left(1-\bar{x}_{(n)}^{B A}\right) S_{(n)}^{B}\right]^{-1 / \varepsilon_{B}} .
\end{aligned}
$$

Step 9. If $n<1,020$, go back to Step 2. Otherwise, proceed to Step 10.

Step 10. Discard observations for $n<500$ and stop.

The cases of fixed supply and fixed and endogenous transfer costs are straightforward variations of the algorithm described and are omitted in the interest of space.

The equilibrium values $\bar{x}_{(n)}^{A B}$ and $\bar{x}_{(n)}^{B A}$ that simultaneously solve the complementary slackness conditions (A2a) and (A2b) in Step (5) are found by means of the bisection method. The main advantage of this method is its robustness in computing the root of continuous realvalued functions defined on a bounded interval. In our model, $\bar{x}_{(n)}^{A B}$ and $\bar{x}_{(n)}^{B A}$ are bounded because, as stated earlier, $\bar{x}_{(n)}^{i j} \in[0,1)$ for $i \neq j$. Further, the solution is such that $\bar{x}_{(n)}^{A B} \times \bar{x}_{(n)}^{B A}$ $=0$. The first 500 simulated observations are eliminated in Step 10 to reduce the bias due to the initialization values (i.e., they are used as a burning period). To enhance the estimation of the distributions of the parameter estimates obtained by applying threshold cointegration methods, antithetic replications (Geweke, 1988) of the samples were employed. That is, the random shocks for 500 of the samples were antithetic replications of the corresponding shocks used for the other 500 samples.

\section{References}

Geweke, J. 1988. "Antithetic Acceleration of Monte Carlo Integration in Bayesian Inference." Journal of Econometrics 38: 73-90. 


\section{Appendix B: Results for Other Scenarios}

The following tables report the results corresponding to the scenarios omitted from the main text. The differences worthy of notice for the alternative scenarios are briefly discussed next.

In the case of inferences regarding the number of $z_{t}$ regimes in each sample, the scenarios with stochastic transfer costs and with high demand elasticity yield results very similar to the baseline. As expected, the scenarios with high transfer costs (both fixed and stochastic) have a much larger share of true two-regime samples than the baseline (about $66 \%$ vs. $19.8 \%$ ), and almost twice the proportion of samples inferred to have one $I(1) z_{t}$ regime (about $50 \%$ vs. $24.0 \%$ ). Results for the scenarios with endogenous transfer costs and small samples are in between those for the baseline and the high transfer cost scenarios. In contrast, the stochastic supply scenarios have a relatively small share of true two-regime samples (about $10 \%$ ) and no samples inferred to have all $z t$ observations in one $I(1)$ regime. Also, $2.0 \%(24.8 \%)$ of the stochastic supply samples with low (high) autocorrelation are inferred to

contain $P_{t}^{A}$ or $P_{t}^{B}$ that are $I(0)$, and $57.9 \%(42.8 \%)$ of the samples are inferred to have $z_{t}$ observations in one $I(0)$ regime.

In terms of transfer cost estimates, the endogenous transfer costs scenario is the only one that yields some noticeable differences. First, the one-regime cost estimates are upwardly biased (mean of 0.148 vs. a true unconditional mean of 0.124 ). Second, the one- and tworegime cost estimates have standard deviations substantially greater than in other scenarios. Third, the distributions of the cost estimates from the one- and two-regime samples exhibit a marked skew to the right.

The endogenous transfer costs scenario is also the one leading to the greatest differences regarding the speed of price transmission. All of the speed of price transmission estimates under endogenous transfer costs have a substantial downward bias (e.g., the means are $0.73,0.77$, and 0.68 for the inferred one-, two-, and three-regime samples, respectively). Further, when transfer costs are endogenous, the precision of the speed estimates is much smaller for the inferred one- and two-regime samples (e.g., the corresponding standard deviations are 0.19 and 0.24 ). The two high transfer cost scenarios also exhibit speed estimates markedly different from the baseline. More specifically, the speed of price 
transmission is substantially underestimated when transfer costs are high and samples are inferred to have three regimes (e.g., the means are respectively 0.64 and 0.58 for fixed stochastic transfer costs).

Inferences about individual observations for most of the other scenarios are also similar to the ones corresponding to the baseline. However, the two scenarios with high transfer costs and the one with endogenous transfer costs exhibit a greater propensity to misclassify observations with respect to spatial price differential regimes. In the case of high fixed (stochastic) transfer costs, $21.1 \%(24.9 \%)$ of $z_{t}$ observations from inferred three-regime samples are incorrectly categorized as outside the band, compared to $15.6 \%$ in the baseline. In the endogenous transfer cost scenario, about $23 \%$ of $z_{t}$ observations from inferred two- and three-regime samples are misclassified, vs. $6.6 \%$ and $15.9 \%$ respectively for the baseline. 
Table B.2.1. True and inferred number of samples of different types in the High Fixed Transfer Costs scenario.

\begin{tabular}{llccccc}
\hline & & \multicolumn{3}{c}{ True Number of $z_{t}$ Regimes in the Sample } & Row \\
\cline { 3 - 6 } & & \multicolumn{2}{c}{ One } & Two & Three & Total \\
\cline { 3 - 6 } & $P_{t}^{A}$ or $P_{t}^{B}$ are $I(0)$ & 4 & 0 & 76 & 42 & 122 \\
\hline \multirow{2}{*}{ Inferred } & One $I(1)$ & 4 & 0 & 337 & 141 & 482 \\
Number of $z_{t}$ & One $I(0)$ & 3 & 0 & 114 & 9 & 126 \\
Regimes in & Two & 0 & 0 & 130 & 65 & 195 \\
the Sample & Three & 0 & 0 & 4 & 71 & 75 \\
\hline \multirow{2}{*}{ Column Total } & & 11 & 0 & 661 & 328 & 1000 \\
\hline
\end{tabular}

Note: There were 296 samples for which the numerical procedures for the Seo test failed. Consistent with the stated intent of favoring correct inferences, such samples were classified as having cointegrated prices (i.e., it was assumed that for them the Seo test rejected the null of linear no cointegration between $P^{A}$ and $P^{B}$ ).

Table B.2.2. True and inferred number of samples of different types in the Stochastic Transfer Costs scenario.

\begin{tabular}{|c|c|c|c|c|c|c|}
\hline & & \multicolumn{4}{|c|}{ True Number of $z t$ Regimes in the Sample } & \multirow{3}{*}{$\begin{array}{l}\text { Row } \\
\text { Total }\end{array}$} \\
\hline & & \multicolumn{2}{|c|}{ One } & \multirow[t]{2}{*}{ Two } & \multirow[t]{2}{*}{ Three } & \\
\hline & & $I(1)$ & $I(0)$ & & & \\
\hline \multirow{5}{*}{$\begin{array}{l}\text { Inferred } \\
\text { Number of } z t \\
\text { Regimes in } \\
\text { the Sample }\end{array}$} & $P_{t}^{A}$ or $P_{t}^{B}$ are $I(0)$ & 0 & 0 & 30 & 76 & 106 \\
\hline & One $I(1)$ & 0 & 0 & 110 & 137 & 247 \\
\hline & One $I(0)$ & 0 & 0 & 26 & 317 & 343 \\
\hline & Two & 0 & 0 & 17 & 183 & 200 \\
\hline & Three & 0 & 0 & 1 & 103 & 104 \\
\hline \multicolumn{2}{|l|}{ Column Total } & 0 & 0 & 184 & 816 & 1000 \\
\hline
\end{tabular}


Table B.2.3. True and inferred number of samples of different types in the High Stochastic Transfer Costs scenario.

\begin{tabular}{llccccc}
\hline & & \multicolumn{3}{c}{ True Number of $z_{t}$ Regimes in the Sample } & Row \\
\cline { 3 - 6 } & & \multicolumn{2}{c}{ One } & Two & Three & Total \\
\cline { 3 - 6 } & $P_{t}^{A}$ or $P_{t}^{B}$ are $I(0)$ & 1 & 0 & 77 & 42 & 120 \\
\hline \multirow{2}{*}{ Inferred } & One $I(1)$ & 3 & 0 & 331 & 140 & 474 \\
Number of $z_{t}$ & One $I(0)$ & 3 & 0 & 108 & 10 & 121 \\
Regimes in & Two & 0 & 0 & 128 & 74 & 202 \\
the Sample & Three & 0 & 0 & 8 & 75 & 83 \\
\hline \multirow{2}{*}{ Column Total } & & 7 & 0 & 652 & 341 & 1000 \\
\hline
\end{tabular}

Note: There were 313 samples for which the numerical procedures for the Seo test failed. Consistent with the stated intent of favoring correct inferences, such samples were classified as having cointegrated prices (i.e., it was assumed that for them the Seo test rejected the null of linear no cointegration between $P^{A}$ and $P^{B}$ ).

Table B.2.4. True and inferred number of samples of different types in the Endogenous Transfer Costs scenario.

\begin{tabular}{|c|c|c|c|c|c|c|}
\hline & & \multicolumn{4}{|c|}{ True Number of $z t$ Regimes in the Sample } & \multirow{3}{*}{$\begin{array}{l}\text { Row } \\
\text { Total }\end{array}$} \\
\hline & & \multicolumn{2}{|c|}{ One } & \multirow[t]{2}{*}{ Two } & \multirow[t]{2}{*}{ Three } & \\
\hline & & $I(1)$ & $I(0)$ & & & \\
\hline \multirow{5}{*}{$\begin{array}{l}\text { Inferred } \\
\text { Number of } z t \\
\text { Regimes in } \\
\text { the Sample }\end{array}$} & $P_{t}^{A}$ or $P_{t}^{B}$ are $I(0)$ & 0 & 0 & 54 & 66 & 120 \\
\hline & One $I(1)$ & 0 & 0 & 190 & 286 & 476 \\
\hline & One $I(0)$ & 0 & 0 & 110 & 41 & 151 \\
\hline & Two & 0 & 0 & 82 & 97 & 179 \\
\hline & Three & 0 & 0 & 1 & 73 & 74 \\
\hline Column Total & & 0 & 0 & 437 & 563 & 1000 \\
\hline
\end{tabular}


Table B.2.5. True and inferred number of samples of different types in the Small Sample scenario.

\begin{tabular}{llccccc}
\hline & & \multicolumn{3}{c}{ True Number of $z_{t}$ Regimes in the Sample } & Row \\
\cline { 3 - 6 } & & \multicolumn{2}{c}{ One } & Two & Three & Total \\
\cline { 3 - 6 } & $P_{t}^{A}$ or $P_{t}^{B}$ are $I(0)$ & 0 & 0 & 29 & 55 & 84 \\
\hline \multirow{2}{*}{ Inferred } & One $I(1)$ & 0 & 0 & 159 & 165 & 324 \\
Number of $z_{t}$ & One $I(0)$ & 0 & 0 & 50 & 339 & 389 \\
Regimes in & Two & 0 & 0 & 15 & 151 & 166 \\
the Sample & Three & 0 & 0 & 0 & 37 & 37 \\
\hline \multirow{2}{*}{ Column Total } & & 0 & 0 & 253 & 747 & 1000 \\
\hline
\end{tabular}

Note: There were 66 samples for which the numerical procedures for the Seo test failed. Consistent with the stated intent of favoring correct inferences, such samples were classified as having cointegrated prices (i.e., it was assumed that for them the Seo test rejected the null of linear no cointegration between $P^{A}$ and $P^{B}$ ).

Table B.2.6. True and inferred number of samples of different types in the High Demand Elasticity scenario.

\begin{tabular}{|c|c|c|c|c|c|c|}
\hline & & \multicolumn{4}{|c|}{ True Number of $z t$ Regimes in the Sample } & \multirow{3}{*}{$\begin{array}{l}\text { Row } \\
\text { Total }\end{array}$} \\
\hline & & \multicolumn{2}{|c|}{ One } & \multirow[t]{2}{*}{ Two } & \multirow[t]{2}{*}{ Three } & \\
\hline & & $I(1)$ & $I(0)$ & & & \\
\hline \multirow{5}{*}{$\begin{array}{l}\text { Inferred } \\
\text { Number of } z t \\
\text { Regimes in } \\
\text { the Sample }\end{array}$} & $P_{t}^{A}$ or $P_{t}^{B}$ are $I(0)$ & 0 & 0 & 21 & 79 & 100 \\
\hline & One $I(1)$ & 0 & 0 & 96 & 101 & 197 \\
\hline & One $I(0)$ & 0 & 0 & 16 & 368 & 384 \\
\hline & Two & 0 & 0 & 15 & 194 & 209 \\
\hline & Three & 0 & 0 & 1 & 109 & 110 \\
\hline Column Total & & 0 & 0 & 149 & 851 & 1000 \\
\hline
\end{tabular}


Table B.2.7. True and inferred number of samples of different types in the Different Demand Elasticities scenario.

\begin{tabular}{|c|c|c|c|c|c|c|}
\hline & & \multicolumn{4}{|c|}{ True Number of $z_{t}$ Regimes in the Sample } & \multirow{3}{*}{$\begin{array}{l}\text { Row } \\
\text { Total }\end{array}$} \\
\hline & & \multicolumn{2}{|c|}{ One } & \multirow[t]{2}{*}{ Two } & \multirow[t]{2}{*}{ Three } & \\
\hline & & $I(1)$ & $I(0)$ & & & \\
\hline \multirow{5}{*}{$\begin{array}{l}\text { Inferred } \\
\text { Number of } z t \\
\text { Regimes in } \\
\text { the Sample }\end{array}$} & $P_{t}^{A}$ or $P_{t}^{B}$ are $I(0)$ & 0 & 0 & 31 & 77 & 108 \\
\hline & One $I(1)$ & 0 & 0 & 130 & 118 & 248 \\
\hline & One $I(0)$ & 0 & 0 & 5 & 335 & 340 \\
\hline & Two & 0 & 0 & 10 & 184 & 194 \\
\hline & Three & 0 & 0 & 1 & 109 & 110 \\
\hline Column Total & & 0 & 0 & 177 & 823 & 1000 \\
\hline
\end{tabular}

Note: There were 38 samples for which the numerical procedures for the Seo test failed. Consistent with the stated intent of favoring correct inferences, such samples were classified as having cointegrated prices (i.e., it was assumed that for them the Seo test rejected the null of linear no cointegration between $P^{A}$ and $P^{B}$ ).

Table B.2.8. True and inferred number of samples of different types in the Stochastic Supply with Low Autocorrelation scenario.

\begin{tabular}{|c|c|c|c|c|c|c|}
\hline & & \multicolumn{4}{|c|}{ True Number of $z_{t}$ Regimes in the Sample } & \multirow{3}{*}{$\begin{array}{l}\text { Row } \\
\text { Total }\end{array}$} \\
\hline & & \multicolumn{2}{|c|}{ One } & \multirow[t]{2}{*}{ Two } & \multirow[t]{2}{*}{ Three } & \\
\hline & & $I(1)$ & $I(0)$ & & & \\
\hline \multirow{5}{*}{$\begin{array}{l}\text { Inferred } \\
\text { Number of } z t \\
\text { Regimes in } \\
\text { the Sample }\end{array}$} & $P_{t}^{A}$ or $P_{t}^{B}$ are $I(0)$ & 0 & 0 & 0 & 20 & 20 \\
\hline & One $I(1)$ & 0 & 0 & 0 & 0 & 0 \\
\hline & One $I(0)$ & 0 & 0 & 72 & 507 & 579 \\
\hline & Two & 0 & 0 & 17 & 250 & 267 \\
\hline & Three & 0 & 0 & 1 & 133 & 134 \\
\hline \multicolumn{2}{|l|}{ Column Total } & 0 & 0 & 90 & 910 & 1000 \\
\hline
\end{tabular}


Table B.2.9. True and inferred number of samples of different types in the Stochastic Supply with High Autocorrelation scenario.

\begin{tabular}{llccccc}
\hline & & \multicolumn{3}{c}{ True Number of $z_{t}$ Regimes in the Sample } & Row \\
\cline { 3 - 6 } & & \multicolumn{2}{c}{ One } & Two & Three & Total \\
\cline { 3 - 5 } & $P_{t}^{A}$ or $P_{t}^{B}$ are $I(0)$ & 0 & 0 & 57 & 191 & 248 \\
\hline \multirow{2}{*}{ Inferred } & One $I(1)$ & 0 & 0 & 0 & 0 & 0 \\
Number of $z_{t}$ & One $I(0)$ & 0 & 0 & 33 & 395 & 428 \\
Regimes in & Two & 0 & 0 & 10 & 200 & 210 \\
the Sample & Three & 0 & 0 & 0 & 114 & 114 \\
\hline Column Total & & 0 & 0 & 100 & 900 & 1000 \\
\hline
\end{tabular}

Note: There were 16 samples for which the numerical procedures for the Seo test failed. Consistent with the stated intent of favoring correct inferences, such samples were classified as having cointegrated prices (i.e., it was assumed that for them the Seo test rejected the null of linear no cointegration between $P^{A}$ and $P^{B}$ ). 
Stoch. Supply with Low Autocorr.

Note: One-regime is not applicable because none of the samples actually contain only one stationary regime. Three-regime estimates are based only on samples which have both (i) at least $10 \%$ of the price differential observations greater than transfer costs, and (ii) at least $10 \%$ of the price differential observations smaller than transfer costs. 
Stoch. Supply with Low Autocorr.

0.989

$(0.067)$

0.990

[0.873, 1.084]

1.000

$(0.18)$

1.01

(0.077)

$[0.836,1.092]$

1.06

$[0.83,1.36]$

$(0.33)$

Stoch. Supply with High Autocorr.

$(0.20)$

$[0.82,1.36]$

0.99

$[0.39,1.53]$

Note: The true speed of mean transmission equals 1. 
Note: The true speed of mean transmission equals 1. One-regime is not applicable because none of the samples actually contain only one stationary regime. Three-regime estimates are based only on samples which have both (i) at least 10\% of the price differential observations greater than transfer costs, and (ii) at least $10 \%$ of the price differential observations smaller than transfer costs. 
Table B.5.1. Percentages of observations in alternative spatial price differential regimes for the High Fixed Transfer Costs scenario.

A. Conditional on samples inferred to have two $z t$ regimes. $^{\text {a }}$

\begin{tabular}{lcccc}
\hline & & \multicolumn{2}{c}{ True $z_{t}$ Regime $^{\mathrm{c}}$} & \multirow{2}{*}{ Row Total } \\
\cline { 3 - 4 } & & Within Band & Outside Band $^{*}$ & \\
\hline \multirow{2}{*}{ Inferred $z_{t}$ Regime } & Within Band & 60.0 & 1.9 & 61.9 \\
& Outside Band & 1.5 & 36.5 & 38.0 \\
\hline \multirow{2}{*}{ Column Total } & & 61.5 & 38.5 & 100.0 \\
\hline
\end{tabular}

${ }^{\mathrm{a}}$ The table only classifies $19.5 \%$ of the total simulated observations, corresponding to the 195 High Fixed Transfer Costs samples inferred to have two $z_{t}$ regimes.

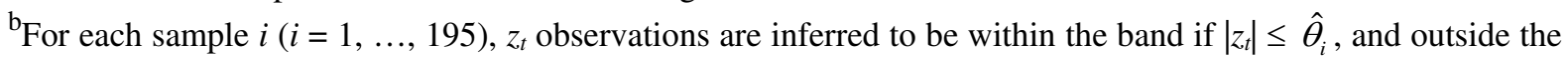
band otherwise, where $\hat{\theta}_{i}$ is the transfer cost estimated using only sample $i$ data.

${ }^{\mathrm{c}}$ The true $z_{t}$ regime is within the band if $\left|z_{t}\right| \leq 0.05$, and is outside the band otherwise.

B. Conditional on samples inferred to have three $z_{t}$ regimes. $^{\text {a }}$

\begin{tabular}{lcccc}
\hline & & \multicolumn{2}{c}{ True $z t$ Regime $^{\mathrm{c}}$} & \multirow{2}{*}{ Row Total } \\
\cline { 3 - 4 } & & Within Band & Outside Band & \\
\hline \multirow{2}{*}{ Inferred $z$ Regime } & & \\
& Within Band & 44.7 & 0.2 & 44.9 \\
\cline { 3 - 4 } Column Total & Outside Band & 21.1 & 34.0 & 55.1 \\
\hline
\end{tabular}

${ }^{a}$ The table only classifies $7.5 \%$ of the total simulated observations, corresponding to the 75 High Fixed Transfer Costs samples inferred to have three $z_{t}$ regimes.

${ }^{\mathrm{b}}$ For each sample $i(i=1, \ldots, 75), z_{t}$ observations are inferred to be within the band if $\left|z_{t}\right| \leq \hat{\theta}_{i}$, and outside the band otherwise, where $\hat{\theta}_{i}$ is the transfer cost estimated using only sample $i$ data.

${ }^{\mathrm{c}}$ The true $z_{t}$ regime is within the band if $\left|z_{t}\right| \leq 0.05$, and is outside the band otherwise. 
Table B.5.2. Percentages of observations in alternative spatial price differential regimes for the Stochastic Transfer Costs scenario.

A. Conditional on samples inferred to have two $z_{t}$ regimes. ${ }^{\text {a }}$

\begin{tabular}{lcccc}
\hline & & \multicolumn{2}{c}{ True $z_{t}$ Regime $^{\mathrm{c}}$} & \multirow{2}{*}{ Row Total } \\
\cline { 3 - 4 } & & Within Band & Outside Band $^{*}$ & \\
\hline \multirow{2}{*}{ Inferred $z_{t}$ Regime } & Within Band & 45.1 & 3.2 & 48.2 \\
& Outside Band & 5.5 & 46.3 & 51.8 \\
\hline \multirow{2}{*}{ Column Total } & & 50.6 & 49.4 & 100.0 \\
\hline
\end{tabular}

${ }^{\mathrm{a}}$ The table only classifies $20.0 \%$ of the total simulated observations, corresponding to the 200 Stochastic Transfer Costs samples inferred to have two $z_{t}$ regimes.

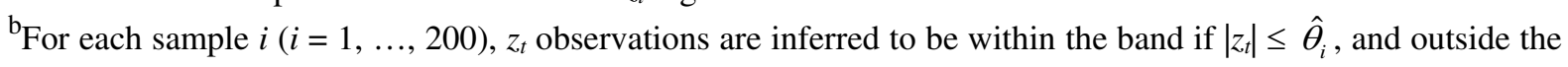
band otherwise, where $\hat{\theta}_{i}$ is the transfer cost estimated using only sample $i$ data.

${ }^{\mathrm{c}}$ The true $z_{t}$ regime is within the band if $\left|z_{t}\right| \leq 0.05$, and is outside the band otherwise.

B. Conditional on samples inferred to have three $z_{t}$ regimes. $^{\mathrm{a}}$

\begin{tabular}{lcccc}
\hline & & \multicolumn{2}{c}{ True $z t$ Regime $^{\mathrm{c}}$} & \multirow{2}{*}{ Row Total } \\
\cline { 3 - 4 } & & Within Band & Outside Band $^{*}$ & \\
\hline \multirow{2}{*}{ Inferred $z$ Regime } & & \\
& Within Band & 36.6 & 1.2 & 37.8 \\
\cline { 3 - 5 } Column Total & Outside Band & 17.6 & 44.6 & 62.2 \\
\hline
\end{tabular}

${ }^{a}$ The table only classifies $10.4 \%$ of the total simulated observations, corresponding to the 104 Stochastic Transfer Costs samples inferred to have three $z_{t}$ regimes.

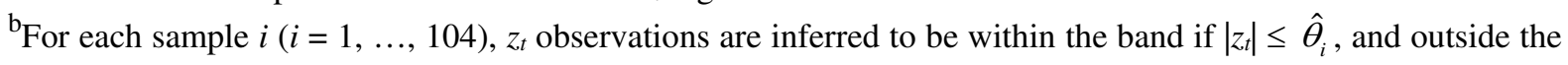
band otherwise, where $\hat{\theta}_{i}$ is the transfer cost estimated using only sample $i$ data.

${ }^{\mathrm{c}}$ The true $z_{t}$ regime is within the band if $\left|z_{t}\right| \leq 0.05$, and is outside the band otherwise. 
Table B.5.3. Percentages of observations in alternative spatial price differential regimes for the High Stochastic Transfer Costs scenario.

A. Conditional on samples inferred to have two $z t$ regimes. $^{\text {a }}$

\begin{tabular}{lcccc}
\hline & & \multicolumn{2}{c}{ True $z_{t}$ Regime $^{\mathrm{c}}$} & \multirow{2}{*}{ Row Total } \\
\cline { 3 - 4 } & & Within Band & Outside Band & \\
\hline \multirow{2}{*}{ Inferred $z_{t}$ Regime $^{\mathrm{b}}{ }^{\mathrm{N}}$} & Within Band & 55.1 & 6.8 & 61.9 \\
\cline { 3 - 5 } Column Total & Outside Band & 7.0 & 31.2 & 38.1 \\
\hline \multirow{2}{*}{ Colunn } & & 62.0 & 38.0 & 100.0 \\
\hline
\end{tabular}

${ }^{\mathrm{a}}$ The table only classifies $20.2 \%$ of the total simulated observations, corresponding to the 202 High Stochastic Transfer Costs samples inferred to have two $z_{t}$ regimes.

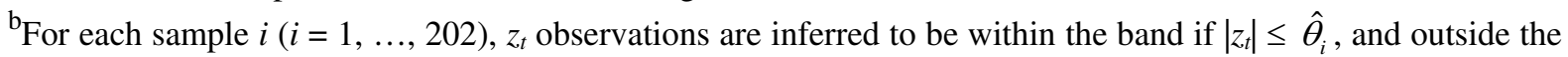
band otherwise, where $\hat{\theta}_{i}$ is the transfer cost estimated using only sample $i$ data.

${ }^{\mathrm{c}}$ The true $z_{t}$ regime is within the band if $\left|z_{t}\right| \leq 0.05$, and is outside the band otherwise.

B. Conditional on samples inferred to have three $z_{t}$ regimes. $^{\mathrm{a}}$

\begin{tabular}{lcccc}
\hline & & \multicolumn{2}{c}{ True $z t$ Regime $^{\mathrm{c}}$} & \multirow{2}{*}{ Row Total } \\
\cline { 3 - 4 } & & Within Band & Outside Band & \\
\hline \multirow{2}{*}{ Inferred $z$ Regime } & & \\
& Within Band & 42.3 & 1.0 & 43.3 \\
\cline { 3 - 4 } Column Total & Outside Band & 24.9 & 31.9 & 56.7 \\
\hline
\end{tabular}

${ }^{a}$ The table only classifies $8.3 \%$ of the total simulated observations, corresponding to the 83 High Stochastic Transfer Costs samples inferred to have three $z_{t}$ regimes.

${ }^{\mathrm{b}}$ For each sample $i(i=1, \ldots, 83), z_{t}$ observations are inferred to be within the band if $\left|z_{t}\right| \leq \hat{\theta}_{i}$, and outside the band otherwise, where $\hat{\theta}_{i}$ is the transfer cost estimated using only sample $i$ data.

${ }^{\mathrm{c}}$ The true $z_{t}$ regime is within the band if $\left|z_{t}\right| \leq 0.05$, and is outside the band otherwise. 
Table B.5.4. Percentages of observations in alternative spatial price differential regimes for the Endogenous Transfer Costs scenario.

A. Conditional on samples inferred to have two $z_{t}$ regimes. $^{\text {a }}$

\begin{tabular}{lcccc}
\hline & & \multicolumn{2}{c}{ True $z_{t}$ Regime $^{\mathrm{c}}$} & \multirow{2}{*}{ Row Total } \\
\cline { 3 - 4 } & & Within Band & Outside Band & \\
\hline \multirow{2}{*}{ Inferred $z_{t}$ Regime $^{\mathrm{b}}{ }^{\mathrm{N}}$} & Within Band & 43.7 & 15.3 & 58.9 \\
\cline { 3 - 5 } & Outside Band & 7.5 & 33.6 & 41.1 \\
\hline \multirow{2}{*}{ Column Total } & & 51.1 & 48.9 & 100.0 \\
\hline
\end{tabular}

${ }^{\mathrm{a}}$ The table only classifies $17.9 \%$ of the total simulated observations, corresponding to the 179 Endogenous Transfer Costs samples inferred to have two $z_{t}$ regimes.

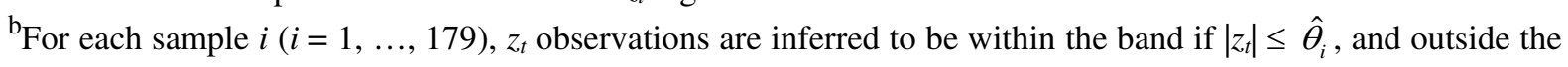
band otherwise, where $\hat{\theta}_{i}$ is the transfer cost estimated using only sample $i$ data.

${ }^{\mathrm{c}}$ The true $z_{t}$ regime is within the band if $\left|z_{t}\right| \leq 0.05$, and is outside the band otherwise.

B. Conditional on samples inferred to have three $z_{t}$ regimes. $^{\text {a }}$

\begin{tabular}{lcccc}
\hline & & \multicolumn{2}{c}{ True $z t$ Regime $^{\mathrm{c}}$} & \multirow{2}{*}{ Row Total } \\
\cline { 3 - 4 } & & Within Band & Outside Band & \\
\hline \multirow{2}{*}{ Inferred $z$ Regime } & & \\
& Within Band & 36.9 & 3.4 & 40.3 \\
\cline { 3 - 4 } Column Total & Outside Band & 19.3 & 40.4 & 59.7 \\
\hline
\end{tabular}

${ }^{\mathrm{a}}$ The table only classifies $7.4 \%$ of the total simulated observations, corresponding to the 74 Endogenous Transfer Costs samples inferred to have three $z_{t}$ regimes.

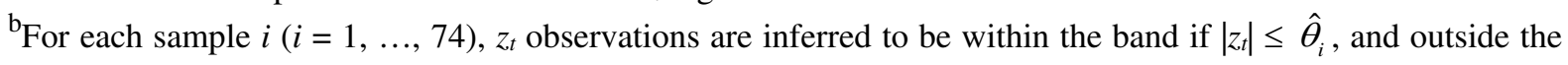
band otherwise, where $\hat{\theta}_{i}$ is the transfer cost estimated using only sample $i$ data.

${ }^{\mathrm{c}}$ The true $z_{t}$ regime is within the band if $\left|z_{t}\right| \leq 0.05$, and is outside the band otherwise. 
Table B.5.5. Percentages of observations in alternative spatial price differential regimes for the Small Sample scenario.

A. Conditional on samples inferred to have two $z t$ regimes. $^{\text {a }}$

\begin{tabular}{lcccc}
\hline & & \multicolumn{2}{c}{ True $z_{t}$ Regime $^{\mathrm{c}}$} & \multirow{2}{*}{ Row Total } \\
\cline { 3 - 4 } & & Within Band & Outside Band $^{*}$ & \\
\hline \multirow{2}{*}{ Inferred $z_{t}$ Regime } & Within Band & 49.1 & 3.5 & 52.6 \\
& Outside Band & 4.5 & 42.9 & 47.4 \\
\hline \multirow{2}{*}{ Column Total } & & 53.6 & 46.4 & 100.0 \\
\hline
\end{tabular}

${ }^{\mathrm{a}}$ The table only classifies $16.6 \%$ of the total simulated observations, corresponding to the 166 Small Sample samples inferred to have two $z_{t}$ regimes.

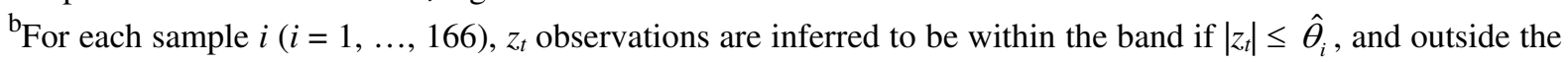
band otherwise, where $\hat{\theta}_{i}$ is the transfer cost estimated using only sample $i$ data.

${ }^{\mathrm{c}}$ The true $z_{t}$ regime is within the band if $\left|z_{t}\right| \leq 0.05$, and is outside the band otherwise.

B. Conditional on samples inferred to have three $z_{t}$ regimes. $^{\text {a }}$

\begin{tabular}{lcccc}
\hline & & \multicolumn{2}{c}{ True $z t$ Regime $^{\mathrm{c}}$} & \multirow{2}{*}{ Row Total } \\
\cline { 3 - 4 } & & Within Band & Outside Band & \\
\hline \multirow{2}{*}{ Inferred $z$ Regime } & & \\
& Within Band & 45.6 & 1.0 & 46.6 \\
\cline { 3 - 4 } Column Total & Outside Band & 11.9 & 41.6 & 53.4 \\
\hline
\end{tabular}

${ }^{\mathrm{a}}$ The table only classifies $3.7 \%$ of the total simulated observations, corresponding to the 37 Small Sample samples inferred to have three $z_{t}$ regimes.

${ }^{\mathrm{b}}$ For each sample $i(i=1, \ldots, 37), z_{t}$ observations are inferred to be within the band if $\left|z_{t}\right| \leq \hat{\theta}_{i}$, and outside the band otherwise, where $\hat{\theta}_{i}$ is the transfer cost estimated using only sample $i$ data.

${ }^{\mathrm{c}}$ The true $z_{t}$ regime is within the band if $\left|z_{t}\right| \leq 0.05$, and is outside the band otherwise. 
Table B.5.6. Percentages of observations in alternative spatial price differential regimes for the High Demand Elasticity scenario.

A. Conditional on samples inferred to have two $z t$ regimes. $^{\text {a }}$

\begin{tabular}{lcccc}
\hline & & \multicolumn{2}{c}{ True $z_{t}$ Regime $^{\mathrm{c}}$} & \multirow{2}{*}{ Row Total } \\
\cline { 3 - 4 } & & Within Band & Outside Band $^{*}$ & \\
\hline \multirow{2}{*}{ Inferred $z_{t}$ Regime } & Within Band & 45.4 & 2.1 & 47.4 \\
& Outside Band & 4.4 & 48.0 & 52.6 \\
\hline \multirow{2}{*}{ Column Total } & & 49.8 & 50.2 & 100.0 \\
\hline
\end{tabular}

${ }^{\mathrm{a}}$ The table only classifies $20.9 \%$ of the total simulated observations, corresponding to the 209 High Demand Elasticity samples inferred to have two $z_{t}$ regimes.

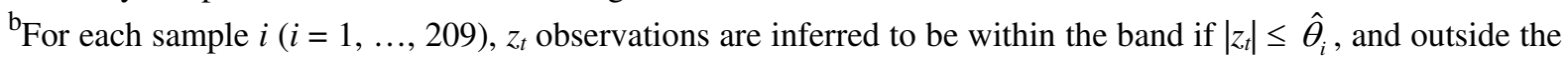
band otherwise, where $\hat{\theta}_{i}$ is the transfer cost estimated using only sample $i$ data.

${ }^{\mathrm{c}}$ The true $z_{t}$ regime is within the band if $\left|z_{t}\right| \leq 0.05$, and is outside the band otherwise.

B. Conditional on samples inferred to have three $z_{t}$ regimes. $^{\text {a }}$

\begin{tabular}{lcccc}
\hline & & \multicolumn{2}{c}{ True $z t$ Regime $^{\mathrm{c}}$} & \multirow{2}{*}{ Row Total } \\
\cline { 3 - 4 } & & Within Band & Outside Band & \\
\hline \multirow{2}{*}{ Inferred $z$ Regime } & & \\
& Within Band & 38.7 & 0.3 & 38.9 \\
\cline { 3 - 4 } Column Total & Outside Band & 16.2 & 44.9 & 61.1 \\
\hline
\end{tabular}

${ }^{\mathrm{a}}$ The table only classifies $11.0 \%$ of the total simulated observations, corresponding to the 110 High Demand Elasticity samples inferred to have three $z_{t}$ regimes.

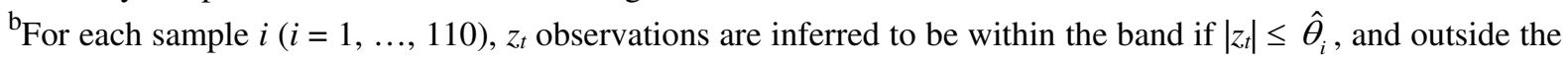
band otherwise, where $\hat{\theta}_{i}$ is the transfer cost estimated using only sample $i$ data.

${ }^{\mathrm{c}}$ The true $z_{t}$ regime is within the band if $\left|z_{t}\right| \leq 0.05$, and is outside the band otherwise. 
Table B.5.7. Percentages of observations in alternative spatial price differential regimes for the Different Demand Elasticities scenario.

A. Conditional on samples inferred to have two $z_{t}$ regimes. $^{\text {a }}$

\begin{tabular}{lcccc}
\hline & & \multicolumn{2}{c}{ True $z_{t}$ Regime $^{\mathrm{c}}$} & \multirow{2}{*}{ Row Total } \\
\cline { 3 - 4 } & & Within Band & Outside Band $^{*}$ & \\
\hline \multirow{2}{*}{ Inferred $z_{t}$ Regime } & Within Band & 45.2 & 2.2 & 47.4 \\
& Outside Band & 4.3 & 48.3 & 52.6 \\
\hline \multirow{2}{*}{ Column Total } & & 49.5 & 50.5 & 100.0 \\
\hline
\end{tabular}

${ }^{\mathrm{a}}$ The table only classifies $19.4 \%$ of the total simulated observations, corresponding to the 194 Different Demand Elasticities samples inferred to have two $z_{t}$ regimes.

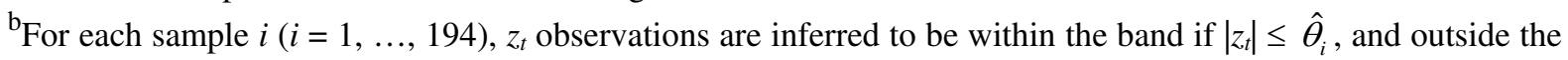
band otherwise, where $\hat{\theta}_{i}$ is the transfer cost estimated using only sample $i$ data.

${ }^{\mathrm{c}}$ The true $z_{t}$ regime is within the band if $\left|z_{t}\right| \leq 0.05$, and is outside the band otherwise.

B. Conditional on samples inferred to have three $z_{t}$ regimes. $^{\text {a }}$

\begin{tabular}{lcccc}
\hline & & \multicolumn{2}{c}{ True $z t$ Regime $^{\mathrm{c}}$} & \multirow{2}{*}{ Row Total } \\
\cline { 3 - 4 } & & Within Band & Outside Band & \\
\hline \multirow{2}{*}{ Inferred $z$ Regime } & & \\
& Within Band & 39.9 & 0.2 & 40.1 \\
\cline { 3 - 4 } Column Total & Outside Band & 15.1 & 44.8 & 59.9 \\
\hline
\end{tabular}

${ }^{\mathrm{a}}$ The table only classifies $11.0 \%$ of the total simulated observations, corresponding to the 110 Different Demand Elasticities samples inferred to have three $z_{t}$ regimes.

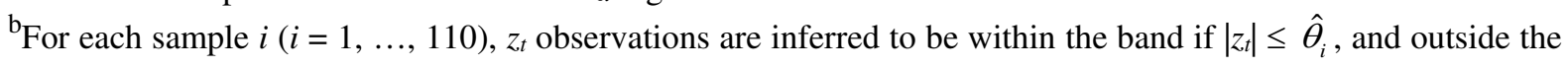
band otherwise, where $\hat{\theta}_{i}$ is the transfer cost estimated using only sample $i$ data.

${ }^{\mathrm{c}}$ The true $z_{t}$ regime is within the band if $\left|z_{t}\right| \leq 0.05$, and is outside the band otherwise. 
Table B.5.8. Percentages of observations in alternative spatial price differential regimes for the Stochastic Supply with Low Autocorrelation scenario.

A. Conditional on samples inferred to have two $z_{t}$ regimes. $^{\text {a }}$

\begin{tabular}{lcccc}
\hline & & \multicolumn{2}{c}{ True $z_{t}$ Regime $^{\mathrm{c}}$} & \multirow{2}{*}{ Row Total } \\
\cline { 3 - 4 } & & Within Band & Outside Band & \\
\hline \multirow{2}{*}{ Inferred $z$ Regime } & & & \\
& Within Band & 44.5 & 1.9 & 46.4 \\
\cline { 3 - 5 } Column Total & Outside Band & 6.0 & 47.6 & 53.6 \\
\hline
\end{tabular}

${ }^{\mathrm{a}}$ The table only classifies $26.7 \%$ of the total simulated observations, corresponding to the 267 Stochastic Supply with Low Autocorrelation samples inferred to have two $z_{t}$ regimes.

${ }^{\mathrm{b}_{F}}$ For each sample $i(i=1, \ldots, 267), z_{t}$ observations are inferred to be within the band if $\left|z_{t}\right| \leq \hat{\theta}_{i}$, and outside the band otherwise, where $\hat{\theta}_{i}$ is the transfer cost estimated using only sample $i$ data.

${ }^{\mathrm{c}}$ The true $z_{t}$ regime is within the band if $\left|z_{t}\right| \leq 0.05$, and is outside the band otherwise.

B. Conditional on samples inferred to have three $z_{t}$ regimes. $^{\mathrm{a}}$

\begin{tabular}{lcccc}
\hline & & \multicolumn{2}{c}{ True $z t$ Regime $^{\mathrm{c}}$} & \multirow{2}{*}{ Row Total } \\
\cline { 3 - 4 } & & Within Band & Outside Band & \\
\hline \multirow{2}{*}{ Inferred $z$ Regime } & & \\
& Within Band & 42.4 & 0.4 & 42.8 \\
\cline { 3 - 4 } Column Total & Outside Band & 14.0 & 43.2 & 57.2 \\
\hline
\end{tabular}

${ }^{a}$ The table only classifies $13.4 \%$ of the total simulated observations, corresponding to the 134 Stochastic Supply with Low Autocorrelation samples inferred to have three $z_{t}$ regimes.

${ }^{\mathrm{b}}$ For each sample $i(i=1, \ldots, 134), z_{t}$ observations are inferred to be within the band if $\left|z_{t}\right| \leq \hat{\theta}_{i}$, and outside the band otherwise, where $\hat{\theta}_{i}$ is the transfer cost estimated using only sample $i$ data.

${ }^{\mathrm{c}}$ The true $z_{t}$ regime is within the band if $\left|z_{t}\right| \leq 0.05$, and is outside the band otherwise. 
Table B.5.9. Percentages of observations in alternative spatial price differential regimes for the Stochastic Supply with High Autocorrelation scenario.

A. Conditional on samples inferred to have two $z_{t}$ regimes. $^{\text {a }}$

\begin{tabular}{lcccc}
\hline & & \multicolumn{2}{c}{ True $z_{t}$ Regime $^{\mathrm{c}}$} & \multirow{2}{*}{ Row Total } \\
\cline { 3 - 4 } & & Within Band & Outside Band & \\
\hline \multirow{2}{*}{ Inferred $z$ Regime } & & & \\
& Within Band & 43.7 & 2.5 & 46.2 \\
\cline { 3 - 5 } Column Total & Outside Band & 4.6 & 49.2 & 53.8 \\
\hline
\end{tabular}

${ }^{\mathrm{a}}$ The table only classifies $21.0 \%$ of the total simulated observations, corresponding to the 210 Stochastic Supply with High Autocorrelation samples inferred to have two $z_{t}$ regimes.

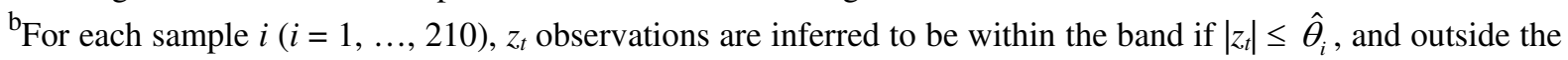
band otherwise, where $\hat{\theta}_{i}$ is the transfer cost estimated using only sample $i$ data.

${ }^{\mathrm{c}}$ The true $z_{t}$ regime is within the band if $\left|z_{t}\right| \leq 0.05$, and is outside the band otherwise.

B. Conditional on samples inferred to have three $z_{t}$ regimes. $^{\mathrm{a}}$

\begin{tabular}{lcccc}
\hline & & \multicolumn{2}{c}{ True $z t$ Regime $^{\mathrm{c}}$} & \multirow{2}{*}{ Row Total } \\
\cline { 3 - 4 } & & Within Band & Outside Band & \\
\hline \multirow{2}{*}{ Inferred $z$ Regime } & & \\
& Within Band & 43.8 & 0.4 & 44.2 \\
\cline { 3 - 4 } Column Total & Outside Band & 12.2 & 43.6 & 55.8 \\
\hline
\end{tabular}

${ }^{a}$ The table only classifies $11.4 \%$ of the total simulated observations, corresponding to the 114 Stochastic Supply with High Autocorrelation samples inferred to have three $z_{t}$ regimes.

${ }^{\mathrm{b}}$ For each sample $i(i=1, \ldots, 114), z_{t}$ observations are inferred to be within the band if $\left|z_{t}\right| \leq \hat{\theta}_{i}$, and outside the band otherwise, where $\hat{\theta}_{i}$ is the transfer cost estimated using only sample $i$ data.

${ }^{\mathrm{c}}$ The true $z_{t}$ regime is within the band if $\left|z_{t}\right| \leq 0.05$, and is outside the band otherwise. 
Table B.6.1. Percentages of observations in alternative trading regimes for the High Fixed Transfer Costs scenario.

A. Conditional on samples inferred to have two $z t$ regimes. ${ }^{a}$

\begin{tabular}{|c|c|c|c|c|}
\hline & & \multicolumn{2}{|c|}{ True Trading Regime $^{c}$} & \multirow[t]{2}{*}{ Row Total } \\
\hline & & No Trade & Trade & \\
\hline \multirow{2}{*}{ Inferred Trading Regime ${ }^{\mathrm{b}}$} & No Trade & 23.5 & 38.4 & 61.9 \\
\hline & Trade & 1.7 & 36.3 & 38.1 \\
\hline Column Total & & 25.2 & 74.8 & 100.0 \\
\hline
\end{tabular}

${ }^{\mathrm{a}}$ The table only classifies $19.5 \%$ of the total simulated observations, corresponding to the 195 High Fixed Transfer Costs samples inferred to have two $z_{t}$ regimes.

${ }^{\mathrm{b}}$ For each sample $i(i=1, \ldots, 195)$, "no trade" is inferred if $\left|z_{t}\right| \leq \hat{\theta}_{i}$, and "trade" is inferred otherwise, where $\hat{\theta}_{i}$ is the transfer cost estimated using only sample $i$ data.

"The true regime is "no trade" if trade did not occur, and "trade" otherwise.

B. Conditional on samples inferred to have three $z t$ regimes. $^{\text {a }}$

\begin{tabular}{lcccc}
\hline & & \multicolumn{2}{c}{ True Trading Regime $^{\mathrm{c}}$} & \multirow{2}{*}{ Row Total } \\
\cline { 3 - 4 } & & No Trade & Trade & \\
\hline \multirow{2}{*}{ Inferred Trading Regime } & No Trade & 26.0 & 18.9 & 44.9 \\
& Trade & 9.1 & 46.0 & 55.1 \\
\hline \multirow{2}{*}{ Column Total } & & 35.1 & 64.9 & 100.0 \\
\hline
\end{tabular}

${ }^{\mathrm{a}}$ The table only classifies $7.5 \%$ of the total simulated observations, corresponding to the 75 High Fixed Transfer Costs samples inferred to have three $z_{t}$ regimes.

bFor each sample $i(i=1, \ldots, 75)$, "no trade" is inferred if $\left|z_{t}\right| \leq \hat{\theta}_{i}$, and "trade" is inferred otherwise, where $\hat{\theta}_{i}$ is the transfer cost estimated using only sample $i$ data.

cThe true regime is "no trade" if trade did not occur, and "trade" otherwise. 
Table B.6.2. Percentages of observations in alternative trading regimes for the Stochastic Transfer Costs scenario.

A. Conditional on samples inferred to have two $z t$ regimes. ${ }^{a}$

\begin{tabular}{lcccc}
\hline & & \multicolumn{2}{c}{ True Trading Regime $^{\mathrm{c}}$} & \multirow{2}{*}{ Row Total } \\
\cline { 3 - 4 } & & No Trade & Trade & \\
\hline \multirow{2}{*}{ Inferred Trading Regime } & bo Trade & 7.0 & 41.3 & 48.2 \\
& Trade & 2.4 & 49.3 & 51.8 \\
\hline \multirow{2}{*}{ Column Total } & & 9.4 & 90.6 & 100.0 \\
\hline
\end{tabular}

${ }^{\mathrm{a}}$ The table only classifies $20.0 \%$ of the total simulated observations, corresponding to the 200 Stochastic Transfer Costs samples inferred to have two $z_{t}$ regimes.

${ }^{\mathrm{b}}$ For each sample $i(i=1, \ldots, 200)$, "no trade" is inferred if $\left|z_{t}\right| \leq \hat{\theta}_{i}$, and "trade" is inferred otherwise, where $\hat{\theta}_{i}$ is the transfer cost estimated using only sample $i$ data.

"The true regime is "no trade" if trade did not occur, and "trade" otherwise.

B. Conditional on samples inferred to have three $z t$ regimes. $^{\text {a }}$

\begin{tabular}{lcccc}
\hline & & \multicolumn{2}{c}{ True Trading Regime $^{\mathrm{c}}$} & \multirow{2}{*}{ Row Total } \\
\cline { 3 - 4 } & & No Trade & Trade & \\
\hline \multirow{2}{*}{ Inferred Trading Regime } & & \\
& No Trade & 11.0 & 26.8 & 37.8 \\
\cline { 3 - 4 } Column Total & Trade & 4.6 & 57.6 & 62.2 \\
\hline
\end{tabular}

${ }^{a}$ The table only classifies $10.4 \%$ of the total simulated observations, corresponding to the 104 Stochastic Transfer Costs samples inferred to have three $z_{t}$ regimes.

${ }^{\mathrm{b}}$ For each sample $i(i=1, \ldots, 104)$, "no trade" is inferred if $\left|z_{t}\right| \leq \hat{\theta}_{i}$, and "trade" is inferred otherwise, where $\hat{\theta}_{i}$ is the transfer cost estimated using only sample $i$ data.

"The true regime is "no trade" if trade did not occur, and "trade" otherwise. 
Table B.6.3. Percentages of observations in alternative trading regimes for the High

Stochastic Transfer Costs scenario.

A. Conditional on samples inferred to have two $z_{t}$ regimes. ${ }^{\mathrm{a}}$

\begin{tabular}{|c|c|c|c|c|}
\hline & & \multicolumn{2}{|c|}{ True Trading Regime ${ }^{c}$} & \multirow[t]{2}{*}{ Row Total } \\
\hline & & No Trade & Trade & \\
\hline \multirow{2}{*}{ Inferred Trading Regime ${ }^{\mathrm{b}}$} & No Trade & 24.0 & 37.9 & 61.9 \\
\hline & Trade & 2.4 & 35.7 & 38.1 \\
\hline Column Total & & 26.4 & 73.6 & 100.0 \\
\hline
\end{tabular}

${ }^{\mathrm{a}}$ The table only classifies $20.2 \%$ of the total simulated observations, corresponding to the 202 High Stochastic Transfer Costs samples inferred to have two $z_{t}$ regimes.

${ }^{\mathrm{b}}$ For each sample $i(i=1, \ldots, 202)$, "no trade" is inferred if $\left|z_{t}\right| \leq \hat{\theta}_{i}$, and "trade" is inferred otherwise, where $\hat{\theta}_{i}$ is the transfer cost estimated using only sample $i$ data.

"The true regime is "no trade" if trade did not occur, and "trade" otherwise.

B. Conditional on samples inferred to have three $z t$ regimes. $^{\text {a }}$

\begin{tabular}{lcccc}
\hline & & \multicolumn{2}{c}{ True Trading Regime $^{\mathrm{c}}$} & \multirow{2}{*}{ Row Total } \\
\cline { 3 - 4 } & & No Trade & Trade & \\
\hline \multirow{2}{*}{ Inferred Trading Regime } & & \\
& No Trade & 26.7 & 16.6 & 43.3 \\
\cline { 3 - 4 } Column Total & Trade & 10.7 & 46.0 & 56.7 \\
\hline
\end{tabular}

${ }^{\mathrm{a}}$ The table only classifies $8.3 \%$ of the total simulated observations, corresponding to the 83 High Stochastic Transfer Costs samples inferred to have three $z_{t}$ regimes.

bFor each sample $i(i=1, \ldots, 83)$, "no trade" is inferred if $\left|z_{t}\right| \leq \hat{\theta}_{i}$, and "trade" is inferred otherwise, where $\hat{\theta}_{i}$ is the transfer cost estimated using only sample $i$ data.

cThe true regime is "no trade" if trade did not occur, and "trade" otherwise. 
Table B.6.4. Percentages of observations in alternative trading regimes for the Endogenous Transfer Costs scenario.

A. Conditional on samples inferred to have two $z t$ regimes. $^{\text {a }}$

\begin{tabular}{lcccc}
\hline & & \multicolumn{2}{c}{ True Trading Regime $^{\mathrm{c}}$} & \multirow{2}{*}{ Row Total } \\
\cline { 3 - 4 } & & No Trade & Trade & \\
\hline \multirow{2}{*}{ Inferred Trading Regime } & bo Trade & 5.4 & 53.6 & 58.9 \\
& Trade & 0.7 & 40.3 & 41.1 \\
\hline \multirow{2}{*}{ Column Total } & & 6.1 & 93.9 & 100.0 \\
\hline
\end{tabular}

${ }^{\mathrm{a}}$ The table only classifies $17.9 \%$ of the total simulated observations, corresponding to the 179 Endogenous Transfer Costs samples inferred to have two $z_{t}$ regimes.

${ }^{\mathrm{b}}$ For each sample $i(i=1, \ldots, 179)$, "no trade" is inferred if $\left|z_{t}\right| \leq \hat{\theta}_{i}$, and "trade" is inferred otherwise, where $\hat{\theta}_{i}$ is the transfer cost estimated using only sample $i$ data.

"The true regime is "no trade" if trade did not occur, and "trade" otherwise.

B. Conditional on samples inferred to have three $z t$ regimes. $^{\text {a }}$

\begin{tabular}{lcccc}
\hline & & \multicolumn{2}{c}{ True Trading Regime $^{\mathrm{c}}$} & \multirow{2}{*}{ Row Total } \\
\cline { 3 - 4 } & & No Trade & Trade & \\
\hline \multirow{2}{*}{ Inferred Trading Regime } & & \\
& No Trade & 14.0 & 26.3 & 40.3 \\
\cline { 3 - 4 } Column Total & Trade & 3.3 & 56.4 & 59.7 \\
\hline
\end{tabular}

${ }^{\mathrm{a}}$ The table only classifies $7.4 \%$ of the total simulated observations, corresponding to the 74 Endogenous Transfer Costs samples inferred to have three $z_{t}$ regimes.

bor each sample $i(i=1, \ldots, 74)$, "no trade" is inferred if $\left|z_{t}\right| \leq \hat{\theta}_{i}$, and "trade" is inferred otherwise, where $\hat{\theta}_{i}$ is the transfer cost estimated using only sample $i$ data.

"The true regime is "no trade" if trade did not occur, and "trade" otherwise. 
Table B.6.5. Percentages of observations in alternative trading regimes for the Small Sample scenario.

A. Conditional on samples inferred to have two $z t$ regimes. $^{a}$

\begin{tabular}{lcccc}
\hline & & \multicolumn{2}{c}{ True Trading Regime } & \multirow{2}{*}{ Row Total } \\
\cline { 3 - 4 } & & No Trade & Trade & \\
\hline \multirow{2}{*}{ Inferred Trading Regime } & bo Trade & 11.6 & 41.0 & 52.6 \\
& Trade & 3.5 & 43.9 & 47.4 \\
\hline \multirow{2}{*}{ Column Total } & & 15.1 & 84.9 & 100.0 \\
\hline
\end{tabular}

${ }^{\mathrm{a}}$ The table only classifies $16.6 \%$ of the total simulated observations, corresponding to the 166 Small Sample samples inferred to have two $z_{t}$ regimes.

${ }^{\mathrm{b}}$ For each sample $i(i=1, \ldots, 166)$, "no trade" is inferred if $\left|z_{t}\right| \leq \hat{\theta}_{i}$, and "trade" is inferred otherwise, where $\hat{\theta}_{i}$ is the transfer cost estimated using only sample $i$ data.

"The true regime is "no trade" if trade did not occur, and "trade" otherwise.

B. Conditional on samples inferred to have three $z t$ regimes. $^{\text {a }}$

\begin{tabular}{lcccc}
\hline & & \multicolumn{2}{c}{ True Trading Regime $^{\mathrm{c}}$} & \multirow{2}{*}{ Row Total } \\
\cline { 3 - 4 } & & No Trade & Trade & \\
\hline \multirow{2}{*}{ Inferred Trading Regime } & & & \\
& No Trade & 19.0 & 27.6 & 46.6 \\
\cline { 3 - 4 } Column Total & Trade & 5.0 & 48.4 & 53.4 \\
\hline
\end{tabular}

${ }^{a}$ The table only classifies $3.7 \%$ of the total simulated observations, corresponding to the 37 Small Sample samples inferred to have three $z_{t}$ regimes.

bFor each sample $i(i=1, \ldots, 37)$, "no trade" is inferred if $\left|z_{t}\right| \leq \hat{\theta}_{i}$, and "trade" is inferred otherwise, where $\hat{\theta}_{i}$ is the transfer cost estimated using only sample $i$ data.

"The true regime is "no trade" if trade did not occur, and "trade" otherwise. 
Table B.6.6. Percentages of observations in alternative trading regimes for the High Demand Elasticity scenario.

A. Conditional on samples inferred to have two $z t$ regimes. $^{\text {a }}$

\begin{tabular}{lcccc}
\hline & & \multicolumn{2}{c}{ True Trading Regime } & \multirow{2}{*}{ Row Total } \\
\cline { 3 - 4 } & & No Trade & Trade & \\
\hline \multirow{2}{*}{ Inferred Trading Regime } & bo Trade & 6.5 & 41.0 & 47.4 \\
& Trade & 2.3 & 50.2 & 52.6 \\
\hline \multirow{2}{*}{ Column Total } & & 8.8 & 91.2 & 100.0 \\
\hline
\end{tabular}

${ }^{\mathrm{a}}$ The table only classifies $20.9 \%$ of the total simulated observations, corresponding to the 209 High Demand Elasticity samples inferred to have two $z_{t}$ regimes.

${ }^{\mathrm{b}}$ For each sample $i(i=1, \ldots, 209)$, "no trade" is inferred if $\left|z_{t}\right| \leq \hat{\theta}_{i}$, and "trade" is inferred otherwise, where $\hat{\theta}_{i}$ is the transfer cost estimated using only sample $i$ data.

"The true regime is "no trade" if trade did not occur, and "trade" otherwise.

B. Conditional on samples inferred to have three $z_{t}$ regimes. ${ }^{\mathrm{a}}$

\begin{tabular}{lcccc}
\hline & & \multicolumn{2}{c}{ True Trading Regime $^{\mathrm{c}}$} & \multirow{2}{*}{ Row Total } \\
\cline { 3 - 4 } & & No Trade & Trade & \\
\hline \multirow{2}{*}{ Inferred Trading Regime } & & \\
& No Trade & 12.3 & 26.7 & 38.9 \\
\cline { 3 - 4 } Column Total & Trade & 5.0 & 56.1 & 61.1 \\
\hline
\end{tabular}

${ }^{a}$ The table only classifies $11.0 \%$ of the total simulated observations, corresponding to the 110 High Demand Elasticity samples inferred to have three $z_{t}$ regimes.

${ }^{\mathrm{b}}$ For each sample $i(i=1, \ldots, 110)$, "no trade" is inferred if $\left|z_{t}\right| \leq \hat{\theta}_{i}$, and "trade" is inferred otherwise, where $\hat{\theta}_{i}$ is the transfer cost estimated using only sample $i$ data.

cThe true regime is "no trade" if trade did not occur, and "trade" otherwise. 
Table B.6.7. Percentages of observations in alternative trading regimes for the Different Demand Elasticities scenario.

A. Conditional on samples inferred to have two $z t$ regimes. $^{\text {a }}$

\begin{tabular}{lcccc}
\hline & & \multicolumn{2}{c}{ True Trading Regime } & \multirow{2}{*}{ Row Total } \\
\cline { 3 - 4 } & & No Trade & Trade & \\
\hline \multirow{2}{*}{ Inferred Trading Regime } & bo Trade & 6.0 & 41.3 & 47.3 \\
& Trade & 2.3 & 50.4 & 52.7 \\
\hline \multirow{2}{*}{ Column Total } & & 8.3 & 91.7 & 100.0 \\
\hline
\end{tabular}

${ }^{\mathrm{a}}$ The table only classifies $19.4 \%$ of the total simulated observations, corresponding to the 194 Different Demand Elasticities samples inferred to have two $z_{t}$ regimes.

${ }^{\mathrm{b}}$ For each sample $i(i=1, \ldots, 194)$, "no trade" is inferred if $\left|z_{t}\right| \leq \hat{\theta}_{i}$, and "trade" is inferred otherwise, where $\hat{\theta}_{i}$ is the transfer cost estimated using only sample $i$ data.

"The true regime is "no trade" if trade did not occur, and "trade" otherwise.

B. Conditional on samples inferred to have three $z t$ regimes. $^{\text {a }}$

\begin{tabular}{lcccc}
\hline & & \multicolumn{2}{c}{ True Trading Regime $^{\mathrm{c}}$} & \multirow{2}{*}{ Row Total } \\
\cline { 3 - 4 } & & No Trade & Trade & \\
\hline \multirow{2}{*}{ Inferred Trading Regime } & & \\
& No Trade & 11.8 & 28.3 & 40.1 \\
& Trade & 5.0 & 54.9 & 59.9 \\
\hline \multirow{2}{*}{ Column Total } & & 16.8 & 83.2 & 100.0 \\
\hline
\end{tabular}

${ }^{\mathrm{a}}$ The table only classifies $11.0 \%$ of the total simulated observations, corresponding to the 110 Different Demand Elasticities samples inferred to have three $z_{t}$ regimes.

bFor each sample $i(i=1, \ldots, 110)$, "no trade" is inferred if $\left|z_{t}\right| \leq \hat{\theta}_{i}$, and "trade" is inferred otherwise, where $\hat{\theta}_{i}$ is the transfer cost estimated using only sample $i$ data.

"The true regime is "no trade" if trade did not occur, and "trade" otherwise. 
Table B.6.8. Percentages of observations in alternative trading regimes for the Stochastic Supply with Low Autocorrelation scenario.

A. Conditional on samples inferred to have two $z t$ regimes. $^{\text {a }}$

\begin{tabular}{lcccc}
\hline & & \multicolumn{2}{c}{ True Trading Regime } & \multirow{2}{*}{ Row Total } \\
\cline { 3 - 4 } & & No Trade & Trade & \\
\hline \multirow{2}{*}{ Inferred Trading Regime } & b & & \\
& No Trade & 7.4 & 39.0 & 46.4 \\
& Trade & 2.4 & 51.2 & 53.6 \\
\hline \multirow{2}{*}{ Column Total } & & 9.8 & 90.2 & 100.0 \\
\hline
\end{tabular}

${ }^{\mathrm{a}}$ The table only classifies $26.7 \%$ of the total simulated observations, corresponding to the 267 Stochastic Supply with Low Autocorrelation samples inferred to have two $z_{t}$ regimes.

${ }^{\mathrm{b}}$ For each sample $i(i=1, \ldots, 267)$, "no trade" is inferred if $\left|z_{t}\right| \leq \hat{\theta}_{i}$, and "trade" is inferred otherwise, where $\hat{\theta}_{i}$ is the transfer cost estimated using only sample $i$ data.

"The true regime is "no trade" if trade did not occur, and "trade" otherwise.

B. Conditional on samples inferred to have three $z t$ regimes. $^{\text {a }}$

\begin{tabular}{lcccc}
\hline & & \multicolumn{2}{c}{ True Trading Regime $^{\mathrm{c}}$} & \multirow{2}{*}{ Row Total } \\
\cline { 3 - 4 } & & No Trade & Trade & \\
\hline \multirow{2}{*}{ Inferred Trading Regime } & No Trade & 14.4 & 28.4 & 42.8 \\
& Trade & 5.0 & 52.2 & 57.2 \\
\hline \multirow{2}{*}{ Column Total } & & 19.4 & 80.6 & 100.0 \\
\hline
\end{tabular}

${ }^{\mathrm{a}}$ The table only classifies $13.4 \%$ of the total simulated observations, corresponding to the 134 Stochastic Supply with Low Autocorrelation samples inferred to have three $z_{t}$ regimes.

${ }^{\mathrm{b}}$ For each sample $i(i=1, \ldots, 134)$, "no trade" is inferred if $\left|z_{t}\right| \leq \hat{\theta}_{i}$, and "trade" is inferred otherwise, where $\hat{\theta}_{i}$ is the transfer cost estimated using only sample $i$ data.

"The true regime is "no trade" if trade did not occur, and "trade" otherwise. 
Table B.6.9. Percentages of observations in alternative trading regimes for the Stochastic Supply with High Autocorrelation scenario.

A. Conditional on samples inferred to have two $z t$ regimes. ${ }^{a}$

\begin{tabular}{lcccc}
\hline & & \multicolumn{2}{c}{ True Trading Regime } & \multirow{2}{*}{ Row Total } \\
\cline { 3 - 4 } & & No Trade & Trade & \\
\hline \multirow{2}{*}{ Inferred Trading Regime } & b & & \\
& No Trade & 5.2 & 41.0 & 46.2 \\
& Trade & 2.0 & 51.8 & 53.8 \\
\hline \multirow{2}{*}{ Column Total } & & 7.2 & 92.8 & 100.0 \\
\hline
\end{tabular}

${ }^{\mathrm{a}}$ The table only classifies $21.0 \%$ of the total simulated observations, corresponding to the 210 Stochastic Supply with High Autocorrelation samples inferred to have two $z_{t}$ regimes.

${ }^{\mathrm{b}}$ For each sample $i(i=1, \ldots, 210)$, "no trade" is inferred if $\left|z_{t}\right| \leq \hat{\theta}_{i}$, and "trade" is inferred otherwise, where $\hat{\theta}_{i}$ is the transfer cost estimated using only sample $i$ data.

"The true regime is "no trade" if trade did not occur, and "trade" otherwise.

B. Conditional on samples inferred to have three $z t$ regimes. $^{\text {a }}$

\begin{tabular}{lcccc}
\hline & & \multicolumn{2}{c}{ True Trading Regime $^{\mathrm{c}}$} & \multirow{2}{*}{ Row Total } \\
\cline { 3 - 4 } & & No Trade & Trade & \\
\hline \multirow{2}{*}{ Inferred Trading Regime } & & \\
& No Trade & 13.4 & 30.8 & 44.2 \\
& Trade & 4.8 & 51.0 & 55.8 \\
\hline \multirow{2}{*}{ Column Total } & & 18.3 & 81.7 & 100.0 \\
\hline
\end{tabular}

${ }^{\mathrm{a}}$ The table only classifies $11.4 \%$ of the total simulated observations, corresponding to the 114 Stochastic Supply with High Autocorrelation samples inferred to have three $z_{t}$ regimes.

${ }^{\mathrm{b}}$ For each sample $i(i=1, \ldots, 114)$, "no trade" is inferred if $\left|z_{t}\right| \leq \hat{\theta}_{i}$, and "trade" is inferred otherwise, where $\hat{\theta}_{i}$ is the transfer cost estimated using only sample $i$ data.

"The true regime is "no trade" if trade did not occur, and "trade" otherwise. 